NBER WORKING PAPER SERIES

\title{
LABOR DYNAMICS AND SUPPLY CHAIN DISRUPTION IN FOOD MANUFACTURING
}

\author{
A. Ford Ramsey \\ Barry Goodwin \\ Mildred Haley \\ Working Paper 28896 \\ http://www.nber.org/papers/w28896 \\ NATIONAL BUREAU OF ECONOMIC RESEARCH \\ 1050 Massachusetts Avenue \\ Cambridge, MA 02138 \\ June 2021
}

The findings and conclusions in this paper are those of the authors and should not be construed to represent any official USDA or U.S. Government determination or policy. This research was supported in part by the U.S. Department of Agriculture, Economic Research Service and NIFAAFRI Grant Number 2020-67023-32760: "COVID-19 Rapid Response: Coronavirus Disease 2019, Price Transmission, and the Farm-Retail Price Spread in U.S. Livestock." The views expressed herein are those of the authors and do not necessarily reflect the views of the National Bureau of Economic Research.

NBER working papers are circulated for discussion and comment purposes. They have not been peer-reviewed or been subject to the review by the NBER Board of Directors that accompanies official NBER publications.

(C) 2021 by A. Ford Ramsey, Barry Goodwin, and Mildred Haley. All rights reserved. Short sections of text, not to exceed two paragraphs, may be quoted without explicit permission provided that full credit, including $(\odot$ notice, is given to the source. 
Labor Dynamics and Supply Chain Disruption in Food Manufacturing

A. Ford Ramsey, Barry Goodwin, and Mildred Haley

NBER Working Paper No. 28896

June 2021

JEL No. J2,L66

\begin{abstract}
$\underline{\text { ABSTRACT }}$
Food manufacturing and processing is an important link between agricultural producers and consumers in the agricultural supply chain. The food manufacturing sector in the United States is both increasingly mechanized and increasingly concentrated. Consequently, labor risks in food manufacturing have changed over time with changes in industry structure. Labor risks were highlighted by the COVID-19 pandemic - particularly in the animal slaughtering and processing industry - where labor-driven disruptions resulted in temporary plant closures. We use countylevel data on employment in food manufacturing and dynamic panel models estimated via generalized method of moments to examine employment and wage dynamics in the food manufacturing sector and animal processing industry. We then compare forecasts from the estimated models with changes in food manufacturing and animal processing employment and wages during the onset of the COVID-19 pandemic. Our results provide insight into the role of operational and disruption risks in food manufacturing. We find significant delays in adjustment to employment and quicker adjustment in wages. Although there is an unanticipated drop in employment in food manufacturing and animal processing in April of 2020, employment returned to predicted levels within two to three months. The response of wages and employment to the COVID-19 pandemic suggest a degree of resilience in food supply chains.
\end{abstract}

\author{
A. Ford Ramsey \\ Virginia Tech \\ 202-B Hutcheson Hall \\ 250 Drillfield \\ Blacksburg, VA 24061 \\ aframsey@vt.edu \\ Barry Goodwin \\ Departments of Economics and Agricultural \\ and Resource Economics \\ North Carolina State University \\ Box 8109 \\ Raleigh, NC 27695 \\ barry_goodwin@ncsu.edu
}

\author{
Mildred Haley \\ US Department of Agriculture \\ 805 Pennsylvania Avenue \\ Kansas City, MO 64105 \\ mildred.haley@usda.gov
}




\section{Introduction}

Agricultural supply chains link agricultural producers to consumers and end-users. The nature and organization of the agricultural supply chain has changed drastically over time with increased vertical integration, increased prevalence of contract farming, and specialization in different supply activities (Adjemian, Brorsen, Hahn, Saitone, \& Sexton, 2016; Boehlje, 1999). Firms strategically design supply chains in response to new innovations and technologies (Zilberman, Lu, \& Reardon, 2019). In designing and adopting different organizational structures or technologies, firm owners and managers in the supply chain act in entrepeneurial capacities by reacting to disequilibria in their environment (Schultz, 1975). Disequilibria are uncertain in both frequency and magnitude, resulting in a variety of risks for supply chain participants.

Just as supply chains have changed over time, supply chain risk has also evolved. Many organizational structures and technologies introduced into food supply chains have been aimed at reducing risks faced by participants Antle, 1996, Knoeber \& Thurman, 1995; McCluskey \& O’Rourke, 2000). Supply chain risks can be broadly characterized as either operational risks or disruption risks. Tang (2006) defines operational risk as risks that are inherent to the business, such as uncertain market conditions. In contrast, disruption risks arise from natural disasters or other extreme events. Operational and disruption risks can be closely linked as the same elements of the supply chain that are subject to inherent uncertainty consumer demand, for example - can serve as transmission mechanisms for disruptive events.

A major risk in agricultural supply chains arises from the diverse skills required of workers in the agriculture and food industry labor forces. These risks are compounded by consolidation and increased concentration in food manufacturing and processing, including meatpacking, which has resulted in increased plant size (MacDonald, 2014, MacDonald, Ollinger, Nelson, \& Handy, 2000; Wohlgenant, 2013). Although varying in significance by industry within the food manufacturing sector, labor is a critical input to most manufacturing operations. Huang (2003) shows that changes in labor inputs to food manufacturing are heterogeneous 
across industries; meat products and miscellaneous foods saw increased employment between 1975 and 1997, while other food industries saw decreased employment of production workers. The meatpacking industry employs the most production workers of all food manufacturing industries. Given heterogeneity in the types and uses of labor in food manufacturing, firms face an array of operational and disruption risks related to their labor inputs.

Operational risks can be characterized by empirically modeling industry operation and assessing the flexibility of supply chain participants in responding to changes in the operating environment. For instance, if meatpacking labor is more specialized and harder to acquire than labor in other areas of food manufacturing, we might expect employment in the meatpacking sector to respond more slowly to changes in demand or other factors. There may be significant temporal relationships that affect the ability of firms to adjust to changing market conditions. Accurate assessment of labor and wage flexibility is necessary for characterizing labor-related operational risks faced by firms.

In contrast to operational risks, disruption risk arises from events that may entail a sudden and complete break in the supply chain or firm operations. Probabilities of loss and magnitudes of loss are difficult to assess for disruption risk as disruptive incidents usually occur with low probability and potentially large losses. These characteristics of disruption risk make it difficult for firms to perform cost-benefit analyses or other studies for risk management as the results of such studies can be highly dependent on a small number of disruptive events (Tang, 2006). Firm management may view the probability of such events to be so low that they are not worthy of incorporation in risk management strategies (Kunreuther \& Useem, 2018). Despite difficulties in modeling disruptive events, such events often lead to calls for public policy actions to improve resilience of a system.

The COVID-19 pandemic illustrates the impact of a major disruption in the food manufacturing sector. Impacts occurred at all stages of the supply chain with effects across both demand and supply sides of markets. In particular, labor inputs to food manufacturing were disrupted due to the nature of work in manufacturing facilities. Work routines in food 
manufacturing plants make workers particularly susceptible to infection by respiratory viruses such as SARS-CoV-2. Disruption was most evident in the animal slaughtering and processing sector. On April 12, 2020 Smithfield Foods announced that it would temporarily suspend operations at a plant in Sioux Falls, Idaho in response to a surge in the number of infected workers. At the time, the plant was one of the largest sources of COVID-19 infection in the United States (Bunge, 2020a, 2020b). Many other plants experienced similar local outbreaks of COVID-19 resulting in temporary closures. Plants that remained open and operated at increased speed were associated with higher rates of infection in the counties in which they were located (Taylor, Boulos, \& Almond, 2020).

The supply chain implications of COVID-19 in agriculture have received significant attention. Hobbs (2020) discussed the potential for supply-side disruption due to labor shortages in downstream food processing and transportation. She notes that the nature of the COVID-19 pandemic afforded manufacturing facilities a period of time to make adjustments to manufacturing processes and working environments. Labor issues up and down the supply chain are discussed in Larue (2020). Within food manufacturing, he notes that firms have the ability to reallocate capacity and an industry-wide shutdown would be the most difficult to manage. However, complete shutdowns are extreme measures - likely to be only temporary and he suggests the sector will switch to operation below capacity to implement mitigation measures.

Temporary plant closures and changes in capacity utilization have the potential to result in stockouts and shortages of food at retail. Stockouts were observed in retail establishments for specific products as consumers stockpiled in the early days of the pandemic. However, widespread shortages of food, whether meat, vegetables, processed items, or other items, did not occur (Hobbs, 2021). Many manufacturing plants were operating near capacity by the middle of 2020. While COVID-19 did create a major and unprecedented disruption for food manufacturers and meat processors, rapid response on the part of market participants indicates a degree of resilience. 
Using the COVID-19 pandemic as an example of a major disruptive event related to manufacturing labor (and other market conditions), we investigate labor dynamics in food manufacturing and animal processing and slaughtering using county-level data from the Current Employment Survey compiled by the Bureau of Labor Statistics. We model employment and wage dynamics using dynamic panel models estimated using generalized method of moments (GMM). We then compare employment and wages under the estimated dynamic models with employment and wages during the onset of the COVID-19 pandemic in early 2020.

The dynamic labor demand and wage models allow for interdependencies across space and time to be taken into account when evaluating the impacts of economic shocks. The response of market participants to changes in wages and other relevant economic variables can be assessed. Dynamics in the estimated models are useful in evaluating operational risk; they highlight factors resulting in employment and wage changes as well as capturing the speed of adjustment to changes in these factors. Therefore, the combination of the dynamic models with a COVID-19 event study provides assessment of both operational and disruption risks in food manufacturing and the agricultural supply chain.

\section{Labor and the Food Manufacturing Link in Agricultural Supply Chains}

In spite of increased mechanization in manufacturing, labor remains a major input for food manufacturers and animal processors. The food manufacturing sector defined by the North American Industry Classification System (NAICS) consists of nine constituent industries of which animal slaughtering and processing is one. While farm labor has received extensive treatment in the literature, labor in food manufacturing has garnered less attention (Hertz \& Zahniser, 2013; Richards, 2018). However, labor disruption as a result of the COVID-19 pandemic has brought new focus to employment in food manufacturing. 
Among several studies investigating historical changes in the structure of food manufacturing, Goodwin and Brester (1995) showed that demand elasticities for labor decreased and that the degree of substitutability between inputs increased over much of the second half of the twenty-first century. Their findings with respect to labor were in line with an earlier study of factor demand in food manufacturing conducted by Huang (1991). Contemporary statistics compiled by the Bureau of Labor Statistics show that both total output and employment in food manufacturing have increased over the past thirty years as shown in figure 1. While employment in food manufacturing fell in the early 2000s, a sharp increase in employment occurred from 2010. Also shown in figure 1, sector labor productivity grew until 2005, but has since experienced a modest decline.

[Figure 1 about here.]

Labor is the largest component of the marketing bill for food products. The marketing bill is the difference between the farm value of food and what consumers actually pay for food. In a review of food costs between 1950 and 1997, Elitzak (1999) found labor costs contributed to $55 \%$ of rising marketing bills and that 38.5 cents of every food dollar in 1997 was spent on labor associated with the food industry. Larger price spreads - between farm and retail levels - are typically observed for highly processed foods. Figure 2 shows unit labor costs and average hourly earnings in food manufacturing. Both average hourly earnings and unit labor costs have risen over the past two decades. Unit labor costs increased by nearly 70 percent between 1990 and 2020. Trends of increasing employment and labor costs suggest that labor is an important input to food manufacturing and a potential source of supply chain risk.

[Figure 2 about here.]

Figues 3 and 4 show the distribution of employment and weekly wages in food manufacturing as a whole, and meat processing specifically, across the United States. The meat processing sector is significantly more concentrated compared to food manufacturing. In 
contrast to the early 20th century, when meat processing was largely conducted in urban areas, processing facilities are mostly in rural counties with close proximity to livestock inputs. Rural labor pools may be relatively shallow, resulting in increased frictions in the adjustment of employees and wages.

[Figure 3 about here.]

[Figure 4 about here.]

Figure 5 shows kernel density estimates of the 2019 wage and employment distributions by county for both food manufacturing and animal slaughtering and processing. The average weekly wage in food manufacturing was approximately $\$ 802$ with standard deviation of $\$ 292$. In animal slaughtering and processing the average weekly wage was $\$ 779$ with standard deviation of $\$ 272$. The mean number of employees per establishment was 52 in food manufacturing versus 92 in animal slaughtering and processing. All of the distributions are strongly right skewed. In general, animal slaughtering and processing facilities were larger and employed more workers compared to the average food manufacturing operation in 2019.

[Figure 5 about here.]

Much of the risks associated with labor in food manufacturing are likely to be heterogeneous across firms within an industry. McGuckin, Nguyen, and Reznek (1998) note significant impacts of plant ownership changes in food manufacturing on increased productivity and employment. More generally, variation in wages and frequency of job changes have been shown to be greater within industries compared to across industries (S. Davis \& Haltiwanger, 1992). Wage and employment dynamics are expected to differ between industries in food manufacturing. For instance, animal processing has tended to make higher use of immigrant and undocumented labor which could result in supply chain risk related to immigration policy. Other industries make less use of this type of labor and are insulated from unanticipated policy changes. 
The labor demand created by food manufacturing plants can have large impacts on local economic outcomes, especially when food manufacturing operations are located in rural or otherwise sparsely populated counties. The meatpacking industry is a major source of jobs for low-income and immigrant workers. Artz, Jackson, and Orazem (2010) find that meat packing plants alter the demographics of communities in which they are located, being associated with immigrant populations, as well as populations with limited English-speaking ability. These changing demographics are reflected in local school systems and poverty rates. However, they found little evidence of per capita increases in government spending as a result of this demographic change. Their conclusive findings are similar to those of Artz, Orazem, and Otto (2007).

Plant siting decisions and food manufacturing growth are also related to local labor market conditions. Goetz (1997) shows that establishment growth is associated with lower labor costs, higher educational attainment, higher unemployment rates, and a larger population. Similarly, Among other factors, Henderson and McNamara (2000) found that food manufacturing facilities were more likely to locate in counties with lower average wages. Lambert and McNamara (2009) indicate that both labor availability and the skill level of labor are important for attracting manufacturers. They argue that deeper and more diversified labor pools increase the likelihood of being able to hire workers for all positions. Labor heterogeneity is one of the most important factors attracting food manufacturing operations (D. E. Davis $\&$ Schluter, 2005).

There are relatively few comprehensive studies of labor disruption in food manufacturing which may reflect the low probability of widespread disruptive events. However, case studies of labor disruption in specific firms have been mentioned in the literature. Artz et al. (2010) described a 2008 Immigration and Customs Enforcement raid on an Iowa meatpacking facility in which one-third of all employees were arrested. The operating firm subsequently filed for bankruptcy and closed the plant down. Other notable food manufacturing supply chain disruptions have occurred, but did not arise through labor disruption: for instance, the Tyson 
meatpacking fire of 2019 .

The COVID-19 pandemic caused widespread disruption in food manufacturing with news reports concentrating on the meatpacking sector. These disruptions were the result of working conditions that put workers at high risk of contracting COVID-19. However, Asher, Deb, and Gangaram (2021) found COVID-19 cases and deaths to be heterogenously associated with industries in food manufacturing. Meatpacking plants were associated with higher cases and deaths, but so were seafood processing facilities and bakeries. In contrast, dairy manufacturing facilities were associated with less cases. Asher et al. (2021) suggest that this disparity is related to capital-labor ratios, which are low in meat processing and baking, and much higher in dairy manufacturing.

Cho, Lee, and Winters (2020) report findings on the impacts of COVID-19 on the employment status of food sector workers - including manufacturing workers - up through April of 2020. COVID-19 infection rates locally were found to be associated with a decreased likelihood of continuing to work in the same food industry and increased temporary absence for food manufacturing workers. The percentage of previously employed food and beverage workers who were unemployed increased from March of 2020 to April of 2020. Their findings imply that the impact of COVID-19 on labor in food manufacturing arose not only through plant shutdowns, but also through the individual actions of workers to protect themselves from possible exposure.

The COVID-19 pandemic has prompted calls for increased regulation of meatpacking facilities, and potentially other food manufacturers, due to plant shutdowns. Increasing price spreads between farm and retail levels were observed at the start of the pandemic. However, increased marketing margins can result from a competitive market environment (Lusk, Tonsor, $\&$ Schulz, 2021). Any potential policy actions will need to consider issues of operational and disruption risks in food manufacturing and resilience to shocks. The question is, how flexible are firms during normal operation in terms of adjusting employment, wages, and output, and was their adjustment to the pandemic faster or slower? Both of these elements of labor risk 
in food manufacturing are addressed in the empirical analysis that follows.

\section{Methodology}

We estimate a panel dynamic model of the framework of Holtz-Eakin, Newey, and Rosen (1988), Arellano and Bond (1991), and Blundell and Bond (1998). The general formulation is given by

$$
y_{i t}=\sum_{j=1}^{L} \phi_{j} y_{i, t-j}+\sum_{k=1}^{K} x_{i t k} \beta_{k}+\mu_{i}+\epsilon_{i t}
$$

where $y_{i t}$ is an $m \times 1$ vector of endogenous variables for the $i$ th unit of observation in time $t$. Then $y_{i, t-j}$ are lagged endogenous variables and $x_{i t k}$ is a matrix of exogenous variables. The errors $\epsilon_{i t}$ are assumed to be independent from $x_{i t}$. The fixed effect $\mu_{i}$ is correlated with lagged values of $y$ which induces endogeneity in the lagged values.

As noted above, the data in this case are large in cross-section but the time dimension is relatively small. Estimating a dynamic panel model via ordinary least squares would result in biased estimators as noted in Nickell (1981). If one differences equation 1, then the differenced endogenous variable is correlated with the differenced error term. However, several authors have addressed estimation problems in dynamic panel settings with generalized method of moments (GMM) estimators. These include Holtz-Eakin et al. (1988), Arellano and Bond (1991), Blundell and Bond (1998), and Binder, Hsiao, and Pesaran (2005).

Consider the case of equation 1 where both $L$ and $K$ are equal to one. The basic problem is that the moment condition,

$$
E\left[\Delta y_{i t-1} \nu_{i t}\right]=0
$$

where $\nu_{i t}$ is the differenced error term, is violated. Instruments that are relevant for $\Delta y_{i, t-1}$ and satisfy the moment condition can be used to correct for endogeneity bias. As shown in Arellano and Bond (1991), an intuitive set of instruments is given by all other previous realizations of $y_{i}$. The lagged endogenous variables will not be correlated with the contemporaneous error 
term and are relevant for the contemporaneous value of the dependent variable because the model is autoregressive.

The differenced model for individual $i$ is given by

$$
y_{i}^{d}=X_{i}^{d} \gamma+\nu_{i}^{d}
$$

where

$$
y_{i}^{d}=\left(\begin{array}{c}
\Delta y_{i 3} \\
\Delta y_{i 4} \\
\vdots \\
\Delta y_{i T}
\end{array}\right) \quad X_{i}^{d}=\left(\begin{array}{cc}
\Delta y_{i 2} & \Delta x_{i 3} \\
\Delta y_{i 3} & \Delta x_{i 4} \\
\vdots & \vdots \\
\Delta y_{i, T-1} & \Delta x_{i T}
\end{array}\right) \quad \gamma=\left(\begin{array}{c}
\phi \\
\beta
\end{array}\right) \quad \boldsymbol{\nu}_{i}^{d}=\left(\begin{array}{c}
\nu_{i 3} \\
\nu_{i 4} \\
\vdots \\
\nu_{i T}
\end{array}\right)
$$

with the matrix of instruments given by

$$
Z_{i}^{d}=\left(\begin{array}{cccccccccc}
y_{i 1} & 0 & 0 & 0 & 0 & 0 & \cdots & 0 & 0 & 0 \\
0 & y_{i 1} & y_{i 2} & 0 & 0 & 0 & \cdots & 0 & 0 & 0 \\
0 & 0 & 0 & y_{i 1} & y_{i 2} & y_{i 3} & 0 & \cdots & 0 & 0 \\
\vdots & \vdots & \vdots & \vdots & \vdots & \vdots & \ddots & \vdots & \vdots & \vdots \\
0 & 0 & 0 & 0 & 0 & 0 & 0 & y_{i 1} & \cdots & y_{i, T-2}
\end{array}\right)
$$

Blundell and Bond (1998) implement a system GMM estimator that makes use of additional moment conditions. The gains from the additional moment conditions are typically larger when there is a high degree of autocorrelation in the dependent variable ( $\phi$ is large). The set of equations in equation 3 are augmented by level equations where

$$
y_{i}^{\ell}=X_{i}^{\ell}+{ }_{i}^{\ell}
$$


and

$$
y_{i}^{\ell}=\left(\begin{array}{c}
y_{i 2} \\
y_{i 3} \\
\vdots \\
y_{i T}
\end{array}\right) \quad X_{i}^{\ell}=\left(\begin{array}{cc}
y_{i 1} & x_{i 2} \\
y_{i 2} & x_{i 3} \\
\vdots & \vdots \\
y_{i, T-1} & x_{i T}
\end{array}\right) \quad{ }_{i}^{\ell}=\left(\begin{array}{c}
\nu_{i}+\epsilon_{i 2} \\
\nu_{i}+\epsilon_{i 3} \\
\vdots \\
\nu_{i}+\epsilon_{i T}
\end{array}\right)
$$

The instrument matrix for the full system is given by

$$
Z_{i}=\left(\begin{array}{ccc}
Z_{i}^{d} & 0 & D_{i} \\
0 & Z_{i}^{\ell} & 0
\end{array}\right)
$$

The general formulation is easily extended to settings where both $L$ and $K$ are greater than one.

Robust two-step estimators of the finite sample variance in this setting are biased. Windmeijer (2005) notes the potential for severe downward bias in small samples and proposes a corrected estimator. The proposed corrected estimator is found to perform well in approximating the finite sample variance in simulation, thus resulting in more accurate inference. The Windmeijer (2005) correction essentially involves the use of an additional correction term in estimation of the variance with the correction term disappearing as the sample size grows larger. Although the sample size in the following empirical analysis is relatively large, we utilize the bias-corrected estimator of the variance in estimating the employment and wage equations (as well as a single-equation dynamic model of industry output).

Using dynamic employment and wage models estimated via GMM, we then project employment and wages in each county through 2020 and compare the projections to actual employment and wages in an event study framework (Campbell, Lo, \& MacKinlay, 2012; Kothari \& Warner, 2007). It is important to note that this approach does not constitute a natural experiment because we do not observe a counterfactual. Any results only describe changes in employment and wages under COVID-19 and any other conditions prevailing in 
the market in 2020.

In spite of our inability to isolate labor effects of the COVID-19 pandemic, the event study provides potentially useful evidence about food manufacturing and animal processing resilience in the face of a disruptive event. Firms take equilibrating actions given constraints in the face of disruption. If these actions return employment and wage levels to those implied by the model, and do so quickly, then the food manufacturing and animal processing sectors are by definition resilient. By using county-level data, the event study also permits us to examine if the initial impacts of COVID-19 and the degree of resilience is heterogeneous across counties, which we might expect by virtue of different rates of infection and industry structures.

\section{Empirical Results}

Our empirical application utilizes data collected from the U.S. Bureau of Labor Statistics (BLS) and the U.S. Bureau of Economic Analysis (BEA). A county-level consumer price index (CPI) deflator was constructed using the metropolitan statistical area (MSA) implicit price deflators. MSA and regional data were translated to the county level using the National Bureau of Economic Research (NBER) MSA to County crosswalk data tool. For those counties that were not covered by a BLS-defined MSA or regional area, the state-level non-urban household CPI was used. Price data are taken from the BLS CPI database. We consider four classes of commodities - food, pork, poultry, and beef. All price, income, and wage data were deflated using the county-specific CPI.

County level wages and employment were taken from the BLS Quarterly Census of Employment and Wages. These data include annual and monthly employment statistics for 3- and 4-digit NAICS industry classifications. Two specific industries are of interest in this analysis - food manufacturing and processing (NAICS 311) and animal slaughter and processing (NAICS 3116). As noted previously, the data for food manufacturing and 
processing include animal slaughter and processing as a constituent industry. The data provide a rich assessment of employment and wage patterns at the county level. However, the data do suffer from one shortcoming - wage and employment data are not reported when such reporting would disclose proprietary details of individual firms.

We only consider the subset of counties for which wages and employment are reported $t^{11}$ This likely omits those counties with a small number of workers or employees in the relevant sectors. We also consider county-level data taken from the BEA's Regional Economic Information System (REIS). This data source reports county-level income, population, and a range of potentially relevant economic variables. Our data are observed annually at the county level. However, the BLS reported wages for the first three quarters of 2020. Monthly employment was also available for the associated nine months of 2020. These data allow an evaluation of COVID-19 pandemic effects on wages and employment levels in these two specific industries in 2020 .

The goal of our empirical analysis is to evaluate the factors associated with the level of wages and numbers of employees in the food manufacturing sector and animal slaughter and processing industry. These sectors were impacted significantly by the COVID-19 pandemic suffering widespread disruptions. The drop in capital utilization and industry output was especially acute in these two sectors. This is demonstrated in figure 6, where a significant decline in output and plant capacity utilization is apparent in 2020. However, capacity utilization and output recovered within the first three quarters of 2020 and exceeded levels observed at the end of 2019 by the end of the year.

[Figure 6 about here.]

We jointly estimated wage and employment equations using the dynamic panel estimation procedures described above for all food manufacturing and for animal slaughter and processing. Summary statistics for the variables used to explain wage and employment levels are presented

\footnotetext{
${ }^{1}$ The number of establishments is reported for all counties in the United States. A valuable future research direction would address possible specification biases that may result from nondisclosure data reporting considerations.
} 
in table 1. Food manufacturing as a whole tends to have higher wages and levels of employment over the entirety of the sample. Wages and employment also tend to be less historically variable in food manufacturing as shown by the historical coefficient of variation (CV) for wages and employees in the two industries. Per capita wage income is slightly higher in the counties with meat processing facilities,

We assume that employment and wages are jointly endogenous and are influenced by adjustment lags, which are represented using lagged employment and wages. These adjustment lags may represent labor and wage contracts and agreements or other factors causing frictions in the adjustment process. Preliminary results indicated a faster adjustment for wages, where only a single lagged value was significant. Employment is slower to adjust and required two lags.

[Table 1 about here.]

We estimated the following specifications for the employment and wage equations. In the food manufacturing sector, the employment equation is given by

$$
\begin{aligned}
\text { employees }_{i t}= & \mu_{i}+\text { employees }_{i t-1}+\text { employees }_{i t-2}+\text { establishment }_{i t}+\text { foodcpi }_{i t} \\
& + \text { wage }_{i t}+\text { wagecv }_{i t}+\text { employeescv }_{i t}+\text { pcwageincome }_{i t}+\epsilon_{i t}
\end{aligned}
$$

while the wage equation is given by

$$
\begin{aligned}
\text { wage }_{i t}= & \mu_{i}+\text { wage }_{i t-1}+\text { establishment }_{i t}+\text { foodcpi }_{i t} \\
& + \text { employee }_{i t}+\text { wagecv }_{i t}+\text { employeescv }_{i t}+\text { pcwageincome }_{i t}+\epsilon_{i t}
\end{aligned}
$$


For the animal slaughter and processing industry, the employment equation is given by

$$
\begin{aligned}
\text { employees }_{i t}= & \mu_{i}++ \text { employees }_{i t-1}+\text { employees }_{i t-2}+\text { establishment }_{i t}+\text { porkcpi }_{i t} \\
& + \text { poultrycpi }_{i t}+\text { beefcpi }_{i t}+\text { wage }_{i t}+\text { wagecv }_{i t}+\text { employeesc }_{i t}+\text { pcwageincome }_{i t}+\epsilon_{i t}
\end{aligned}
$$

and the wage equation is given by

$$
\begin{aligned}
\text { wage }_{i t}= & \mu_{i}+\text { wage }_{i t-1}+\text { establishment }_{i t}+\text { porkcpi }_{i t}+\text { poultrycpi }_{i t}+\text { beef }_{c p} i_{i t} \\
& + \text { employees }_{i t}+\text { wagecv }_{i t}+\text { employeesc }_{i t}+\text { pcwageincome }_{i t}+\epsilon_{i t}
\end{aligned}
$$

where counties are indexed by $i$ and time is indexed by $t$. Employment and wages are affected by lagged values, contemporary values of employment and wages, the number of establishments in a county, prices of food and/or meat, historical variation in employment and wages, and per capita wage income in a county.

Parameter estimates and related statistics for the dynamic models for food manufacturing are presented in table 2. The results indicate that average weekly wages in the food processing sector are positively associated with the price of output, as represented by the food CPI. Historical volatility in wages, which is represented using the wage $\mathrm{CV}$, tends to increase real wages. This likely represents a risk premium to workers in counties and years that had volatile wages. In contrast, greater volatility in the number of employees tends to be associated with lower wages. Greater volatility in the availability of labor would be expected to result in lower real wages. Finally, counties and years that realized a higher average wage per person also tended to have higher wages in the food manufacturing sector.

[Table 2 about here.]

Strong lagged effects are apparent for the number of employees in the food manufacturing sector. The first-order autoregressive coefficient is 0.90 , which represents a very slow adjustment over time. This is consistent with expectations in that, although wages may be more 
easily adjusted in response to economic conditions, the actual number of employees is much slower to adjust. This requires hiring and firing of workers and therefore is more likely to involve significant frictions that impair adjustment. Long-term employment agreements are one factor that is likely to slow adjustments in the number of workers.

A scale effect on the number of workers is reflected in the number of establishments. More manufacturing plants would be expected to require a greater number of workers. The real price of food tends to lower the number of workers employed in the food manufacturing sector. This is counter to expectations but may reflect the cost of other unobservable inputs. The endogenous weekly wage does not have a significant effect on the number of workers. A higher historical volatility of wages tends to lower employment. A greater degree of wage volatility may suggest a higher level of risk to both workers and plant managers, thereby leading to a lower level of employment.

We also considered a single-equation dynamic panel model of the value of total output from the food industry. This was represented using the industry-specific total personal income for food, beverage, and tobacco manufacturing. A strong lagged effect with a near unitary autoregressive parameter was found for total output. The number of plants in a county and year is associated with lower total output. However, a higher value for the output, as represented by the food CPI, was associated with greater output. The number of employees was associated with greater output. Higher average wages for workers lower the value of output. Greater volatility of average wages is associated with higher output. However, volatility in the number of workers tends to lower the value of output. This suggests that volatility in the availability of workers tends to have a negative effect on the supply chain and reduces the value of output.

[Table 3 about here.]

The wage and employment analysis was repeated for a much more finely defined industry - animal slaughter and processing. COVID-19 had significant impacts on workers in the meat processing sector, although as noted, there is emerging evidence of similar but apparently 
less newsworthy effects in other areas of food manufacturing (Asher et al., 2021). Employees working on the animal slaughter and meat processing lines spent hours in close proximity to one another and the spread of the virus among plant workers was felt across the beef, pork, and poultry industries. Significant lags in adjustment are apparent for both wages and the number of workers in the industry. A greater number of processing plants increased the number of employees but had no statistically significant impact on wages. Wages were negatively related to pork prices but beef and poultry prices had no impact on wages or employment. A higher number of workers is associated with higher wages. Wages are increased as the volatility of wages rises but are decreased as the volatility of the number of workers increases.

[Table 4 about here.]

A central objective of our analysis is to assess the impacts of COVID-19 on wages and employment in the food and animal processing sectors as a study of disruption risk in the sector. To this end, we utilized BLS wage data for the first three quarters of 2020 and monthly employment through September of 2020. We predicted wages and the number of workers holding all other factors at their 2019 levels. Figure 7 illustrates the implied impact on average wages in the food manufacturing sector across the first three quarters of 2020. The predicted and realized values of wages are plotted alongside a $45^{\circ}$ line. Observations above the line indicate wages that are higher than expected while the converse is true for observations below the line.

In general, wages appear to have been slightly higher than one might have expected, conditional on other economic factors being held constant. The cross-sectional volatility of wages appears to have fallen in the second quarter of 2020. Panel (b) of figure 7 shows a much lower level of dispersion of wages. Higher wages may have been necessary to induce employment in the plants during COVID-19. The lower cross-sectional volatility of wages in the second quarter of 2020 may have been associated with a general slowdown in the entire economy. 
[Figure 7 about here.]

Employment over the first nine months of 2020 is illustrated in Figure 8. Again, observations below the $45^{\circ}$ line represent a case where the number of workers is lower than the model predicts. A subtle pattern of declining employment in April and May is visible. Figure 9 illustrates the proportion of counties that had higher than predicted employment in the food manufacturing sector across the first nine months of 2020. A fall in employment relative to what would have been expected is apparent from March through June. This period was characterized by worsening conditions due to the pandemic.

[Figure 8 about here.]

[Figure 9 about here.]

Predictions of wages and employment in the livestock slaughter and processing sector are presented in Figures 10 and 11. Again, wages appear to have been higher during the first three quarters of 2020 than the model predicted. A lower degree of cross-sectional volatility of wages is again notable for the second quarter. Figure 11 again suggests subtle decreases in employment relative to what was expected. Figure 12 repeats the analysis of the proportion of counties that realized lower and higher levels of employment than were expected. Again, a substantial drop in employment from March through May is apparent.

[Figure 10 about here.]

[Figure 11 about here.]

[Figure 12 about here.]

From the point of view of labor related risks in food manufacturing, several conclusions are apparent from this analysis. First, in terms of operational risks, there are complicated dynamics at play for wages and employment in these industries. While wages are relatively 
quick to adjust, employment is slower. This lag suggests that labor inflexibilities in food manufacturing and animal processing may be a significant source of risk with implications throughout the supply chain. Second, historical variation in wages and employment have impacts on current wages and employment, possibly reflecting risk premia. In terms of disruption risk, there are noticeable impacts of the COVID-19 pandemic on employment and wages, particularly in March, April, and May of 2020. Employment is lower than predicted and wages are higher for most (but not all) counties in the sample. These dynamics are indicative of equilibrating actions on the part of firms and market forces at work.

\section{Conclusion}

We model employment and wages in the food manufacturing sector and animal slaughter and processing industries using dynamic panel models and data at the county level. The estimated models allow us to characterize labor dynamics in these industries and provide insight into the operational risks faced by firms in this environment. We then compare estimated employment and wages with these labor outcomes during a disruptive event. The COVID-19 pandemic had large impacts on employment and wages in early 2020. However, the food manufacturing industry recovered quickly returning to pre-pandemic levels. Taken together, these assessments of operational and disruption risk in food manufacturing suggest that labor risk is an important source of risk in the agricultural supply chain. However, the food manufacturing sector as currently organized is relatively resilient, at least to the types of labor shocks resulting from the pandemic.

This analysis of labor dynamics and disruption in food manufacturing points to several lines of research where the literature on agricultural supply chains might be advanced. First, there are a number of interesting outstanding questions related to food manufacturing and animal processing operations. While this analysis focuses on county-level employment, and makes no distinction between regular and production employees, later work could focus on 
plant-level analysis. By distinguishing between different types of employees, it would be possible to better understand intra-firm changes in the distribution of workers. Presumably any risks associated with labor could also differ across worker types.

Second, richer datasets will enable the use of increasingly sophisticated methodologies for the measurement and analysis of agricultural supply chains. Difficulties in empirically modeling supply chains arise from the oftentimes limited availability of current data and the spatially and temporally dynamic nature of supply chains. On one hand, deterministic models of supply chains can be parameterized and used to examine counterfactual supply chain makeup. On the other, purely empirical models can be developed. In either case, computational and econometric methods will need to be increasingly flexible to account for the complexities of global value chains. Such advances are already being incorporated in supply chain research (Chor, 2019; Yu \& Nagurney, 2013).

Lastly, the expanding literature on supply chain innovation and its relationship to supply chain risk could be expanded to manufacturing labor and labor flexibility. Among the growing literature in this area, Lu, Reardon, and Zilberman (2016), focus on machinery rental at the farm level. Du, Lu, Reardon, and Zilberman (2016) considers a portfolio selection approach to supply chain design using the example of a firm that requires feedstock processing. The focus is on purchase of feedstock or production in-house. Few studies have explicitly considered labor issues in food manufacturing and animal processing although unique labor markets (such as heavy use of immigrant labor) characterize these sectors.

The COVID-19 pandemic presents an opportunity to understand how supply chains respond to major - and potentially prolonged - disruption. At the current time, any measured responses can only be considered short term. Important questions about firms' long run response to the pandemic, especially in the food sector, remain. Has disruption spurred food manufacturers to make permanent adjustments to supply chains and manufacturing operations? Anecdotal evidence suggests that animal processors have made increased use of robotization in processing facilities. If widespread, increased mechanization could lower the 
the number of production workers required in processing with concomitant changes in supply chain risk. 


\section{References}

Adjemian, M., Brorsen, B. W., Hahn, W., Saitone, T. L., \& Sexton, R. J. (2016). Thinning Markets in U.S. Agriculture (Economic Information Bulletin 148). Economic Research Service.

Antle, J. M. (1996). Efficient food safety regulation in the food manufacturing sector. American Journal of Agricultural Economics, 78(5), 1242-1247.

Arellano, M., \& Bond, S. (1991). Some tests of specification for panel data: Monte carlo evidence and an application to employment equations. Review of Economic Studies, $58(2), 277-297$.

Artz, G., Jackson, R., \& Orazem, P. (2010). Is it a jungle out there? Meat packing, immigrants, and rural communities. Journal of Agricultural and Resource Economics, 35(2), 299-315.

Artz, G., Orazem, P., \& Otto, D. (2007). Measuring the impact of meat packing and processing facilities in nonmetropolitan counties: a difference-in-differences approach. American Journal of Agricultural Economics, 89(3), 557-570.

Asher, T., Deb, P., \& Gangaram, A. (2021). Nursing facilities, food manufacturing plants and COVID-19 cases and deaths. Economics Letters, 109800.

Binder, M., Hsiao, C., \& Pesaran, M. H. (2005). Estimation and inference in short panel vector autoregressions with unit roots and cointegration. Econometric Theory, 21, 795-837.

Blundell, R., \& Bond, S. (1998). Initial conditions and moment restrictions in dynamic panel data models. Journal of Econometrics, 87(1), 115-143.

Boehlje, M. (1999). Structural changes in the agricultural industries: how do we measure, analyze and understand them? American Journal of Agricultural Economics, 81(5), $1028-1041$.

Bunge, J. (2020a, April 12). Smithfield CEO Warns of Risks to Pork Supply. Wall Street Journal. 
Bunge, J. (2020b, April 15). Smithfield to close more pork plants over coronavirus pandemic. Wall Street Journal.

Campbell, J. Y., Lo, A. W., \& MacKinlay, A. C. (2012). Event-Study Analysis. In The Econometrics of Financial Markets. Princeton University Press.

Cho, S. J., Lee, J. Y., \& Winters, J. V. (2020). COVID-19 Employment Status Impacts on Food Sector Workers (IZA Discussion Paper). Institute of Labor Economics.

Chor, D. (2019). Modeling global value chains: approaches and insights from economics. In Handbook on Global Value Chains. Edward Elgar Publishing.

Davis, D. E., \& Schluter, G. E. (2005). Labor-force heterogeneity as a source of agglomeration economies in an empirical analysis of county-level determinants of food plant entry. Journal of Agricultural and Resource Economics, 30(3), 480-501.

Davis, S., \& Haltiwanger, J. (1992). Gross job creation, gross job destruction, and employment reallocation. Quarterly Journal of Economics, 107(3), 819-863.

Du, X., Lu, L., Reardon, T., \& Zilberman, D. (2016). Economics of agricultural supply chain design: A portfolio selection approach. American Journal of Agricultural Economics, $98(5), 1377-1388$.

Elitzak, H. (1999). Food cost review, 1950-97 (Agricultural Economic Report 780). Economic Research Service.

Goetz, S. J. (1997). State-and county-level determinants of food manufacturing establishment growth: 1987-93. American Journal of Agricultural Economics, 79 (3), 838-850.

Goodwin, B. K., \& Brester, G. W. (1995). Structural change in factor demand relationships in the US food and kindred products industry. American Journal of Agricultural Economics, $77(1), 69-79$.

Henderson, J. R., \& McNamara, K. T. (2000). The location of food manufacturing plant investments in corn belt counties. Journal of Agricultural and Resource Economics, $25(2), 680-697$.

Hertz, T., \& Zahniser, S. (2013). Is there a farm labor shortage? American Journal of 
Agricultural Economics, 95(2), 476-481.

Hobbs, J. E. (2020). Food supply chains during the COVID-19 pandemic. Canadian Journal of Agricultural Economics/Revue canadienne d'agroeconomie, 68(2), 171-176.

Hobbs, J. E. (2021). The Covid-19 pandemic and meat supply chains. Meat Science, Online.

Holtz-Eakin, D., Newey, W., \& Rosen, H. S. (1988). Estimating vector autoregressions with panel data. Econometrica, 56(6), 1371-1395.

Huang, K. S. (1991). Factor demands in the us food-manufacturing industry. American Journal of Agricultural Economics, 73(3), 615-620.

Huang, K. S. (2003). Food manufacturing productivity and its economic implications (Technical Bulletin 1905). Economic Research Service.

Knoeber, C. R., \& Thurman, W. N. (1995). "don't count your chickens...": Risk and risk shifting in the broiler industry. American Journal of Agricultural Economics, 77(3), 486-496.

Kothari, S. P., \& Warner, J. B. (2007). Econometrics of event studies. In Handbook of empirical corporate finance. Elsevier.

Kunreuther, H., \& Useem, M. (2018). Mastering catastrophic risk: How companies are coping with disruption. Oxford University Press.

Lambert, D. M., \& McNamara, K. T. (2009). Location determinants of food manufacturers in the united states, 2000-2004: are nonmetropolitan counties competitive? Agricultural Economics, 40(6), 617-630.

Larue, B. (2020). Labor issues and COVID-19. Canadian Journal of Agricultural Economics/Revue canadienne d'agroeconomie, 68(2), 231-237.

Lu, L., Reardon, T., \& Zilberman, D. (2016). Supply chain design and adoption of indivisible technology. American Journal of Agricultural Economics, 98(5), 1419-1431.

Lusk, J. L., Tonsor, G. T., \& Schulz, L. L. (2021). Beef and pork marketing margins and price spreads during COVID-19. Applied Economic Perspectives and Policy, 43(1), $4-23$. 
MacDonald, J. M. (2014). Technology, organization, and financial performance in US broiler production (Economic Information Bulletin 126). Economic Research Service.

MacDonald, J. M., Ollinger, M., Nelson, K. E., \& Handy, C. R. (2000). Consolidation in us meatpacking (Agricultural Economic Report 785). Economic Research Service.

McCluskey, J. J., \& O’Rourke, A. D. (2000). Relationships between produce supply firms and retailers in the new food supply chain. Journal of Food Distribution Research, 31, $11-20$.

McGuckin, R. H., Nguyen, S. V., \& Reznek, A. P. (1998). On measuring the impact of ownership change on labor: evidence from US food-manufacturing plant-level data. In Labor statistics measurement issues. University of Chicago Press.

Nickell, S. (1981). Biases in dynamic models with fixed effects. Econometrica, 49(6), $1417-1426$.

Richards, T. J. (2018). Immigration reform and farm labor markets. American Journal of Agricultural Economics, 100(4), 1050-1071.

Schultz, T. W. (1975). The value of the ability to deal with disequilibria. Journal of Economic Literature, $13(3), 827-846$.

Tang, C. S. (2006). Perspectives in supply chain risk management. International Journal of Production Economics, 103(2), 451-488.

Taylor, C. A., Boulos, C., \& Almond, D. (2020). Livestock plants and COVID-19 transmission. Proceedings of the National Academy of Sciences, 117(50), 31706-31715.

Windmeijer, F. (2005). A finite sample correction for the variance of linear efficient two-step gmm estimators. Journal of Econometrics, 126(1), 25-51.

Wohlgenant, M. K. (2013). Competition in the us meatpacking industry. Annual Review of Resource Economics, 5(1), 1-12.

Yu, M., \& Nagurney, A. (2013). Competitive food supply chain networks with application to fresh produce. European Journal of Operational Research, 224(2), 273-282.

Zilberman, D., Lu, L., \& Reardon, T. (2019). Innovation-induced food supply chain design. 
Food Policy, 83, 289-297. 
Figure 1: Food Manufacturing Sector Output, Employment, and Labor Productivity
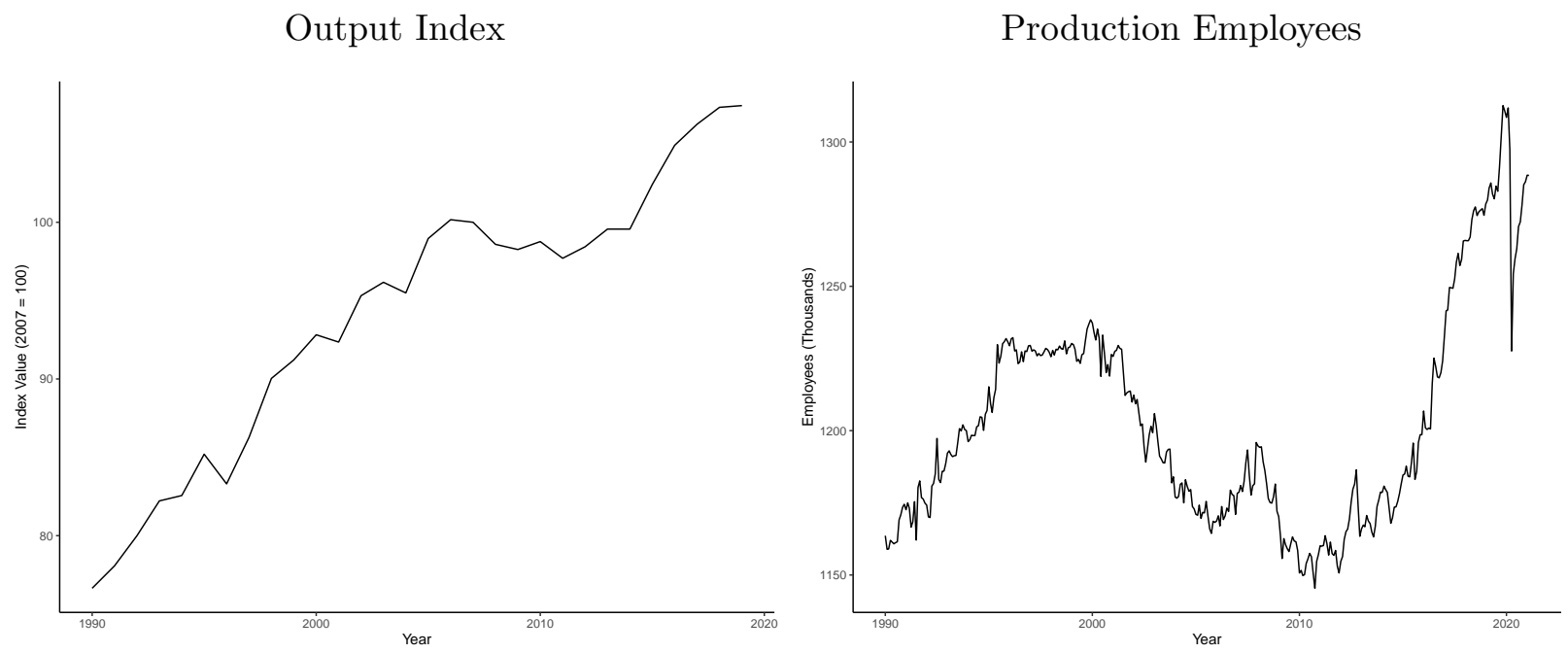

Labor Productivity Index

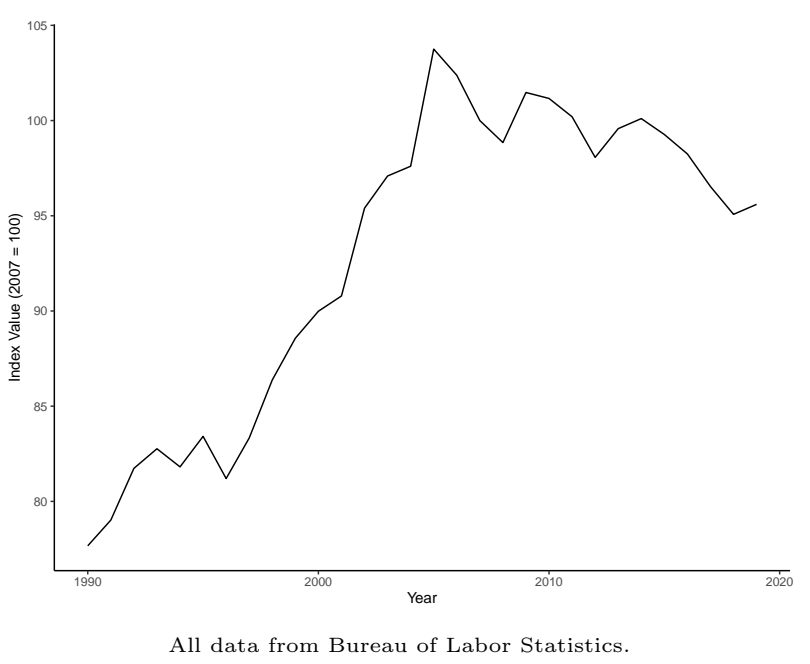


Figure 2: Food Manufacturing Sector Unit Labor Cost and Hourly Wages Unit Labor Cost Index

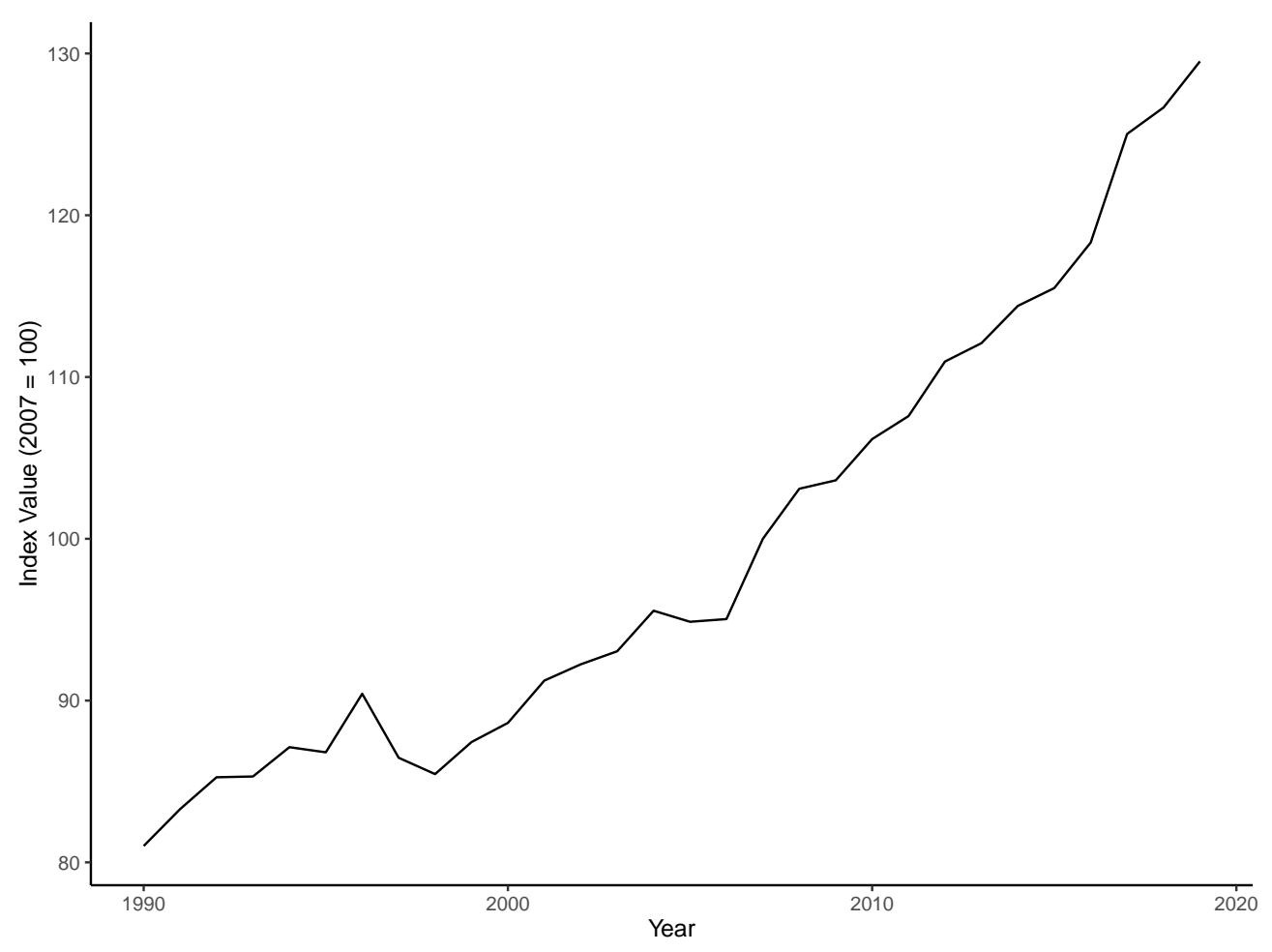

Average Hourly Earnings

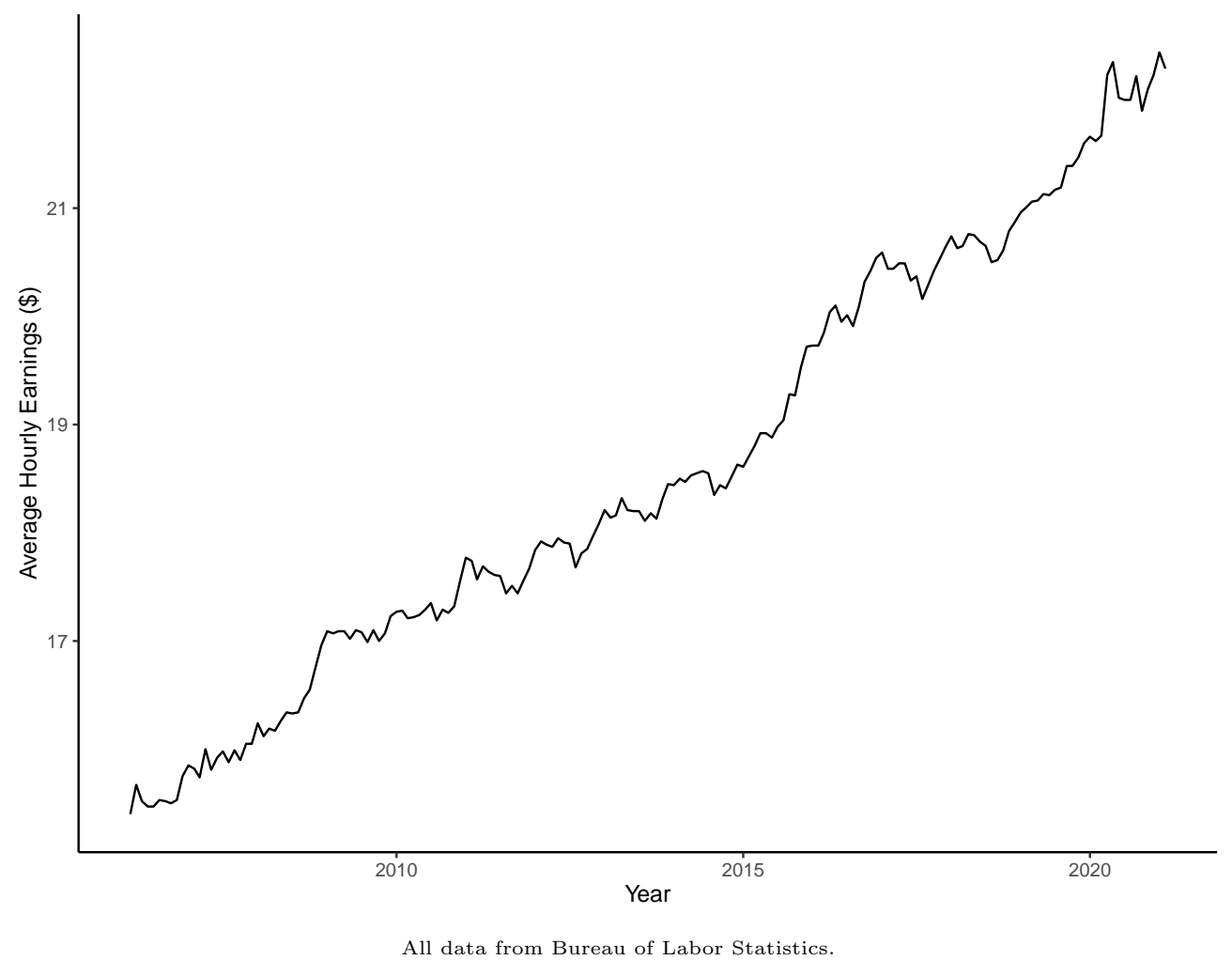


Figure 3: Food Manufacturing Sector Employees and Weekly Wage by County, 2019 Employees

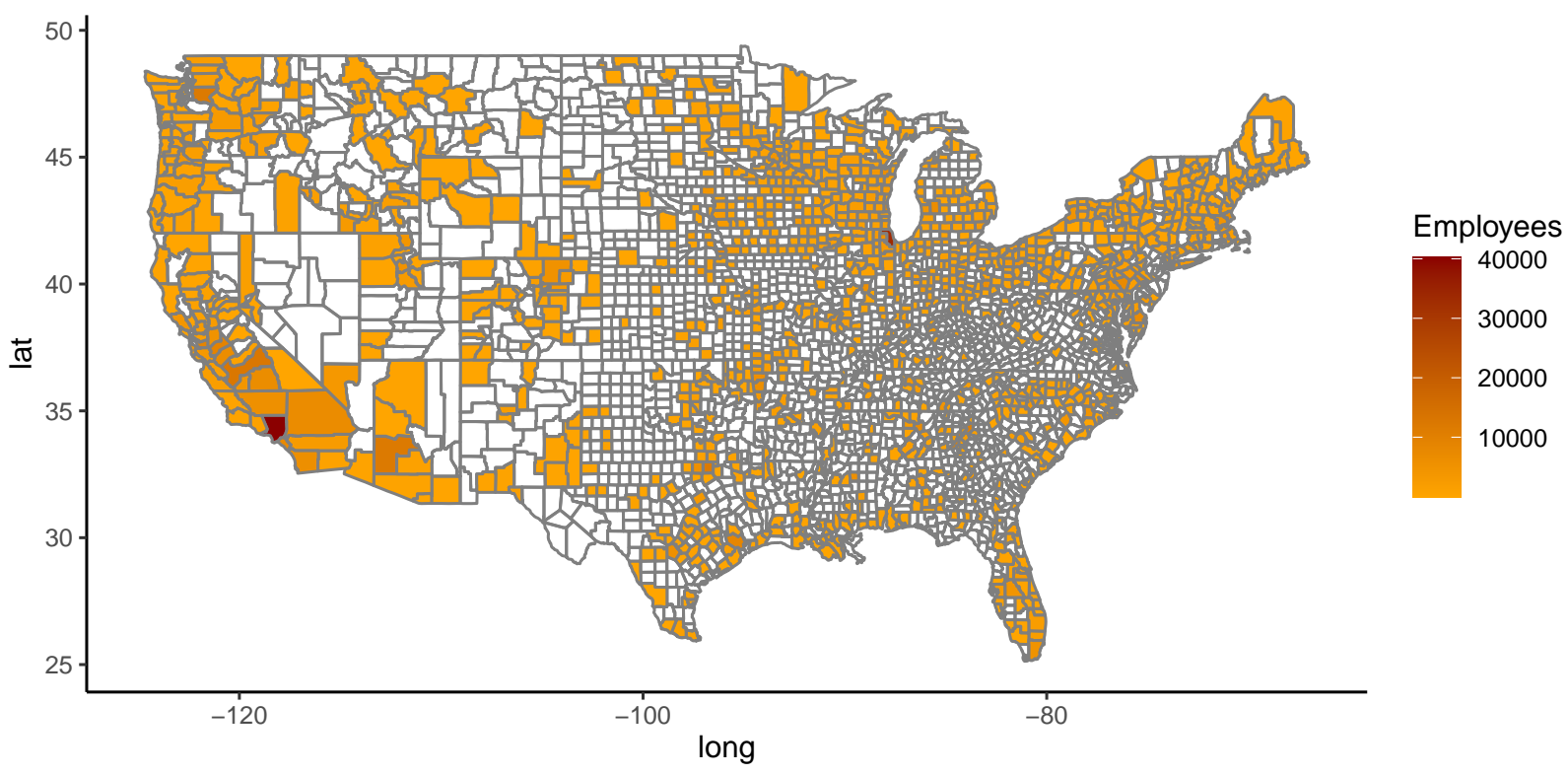

Weekly Wages

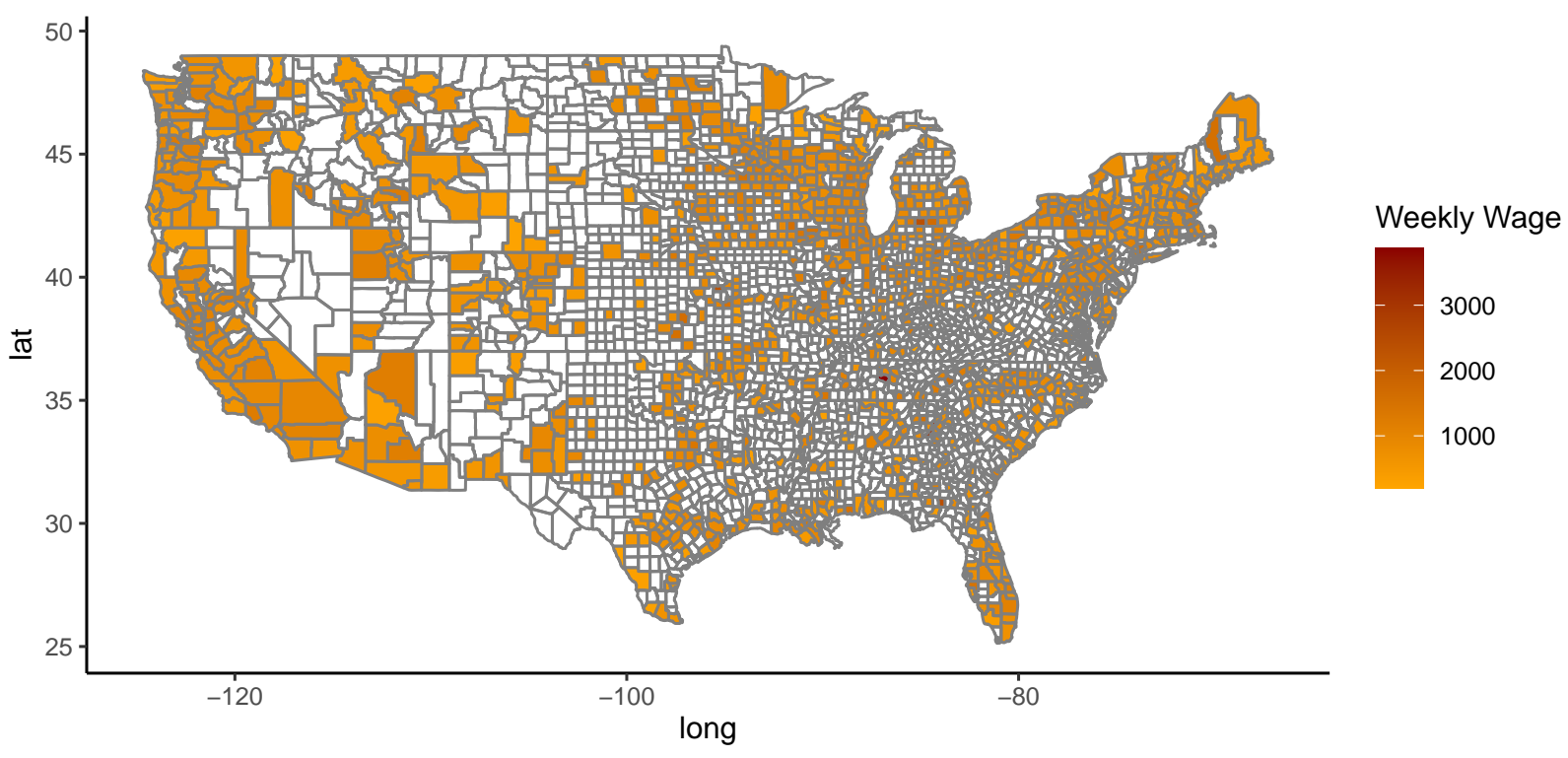

All data from Bureau of Labor Statistics. 
Figure 4: Animal Processing Sector Employees and Weekly Wage by County, 2019 Employees

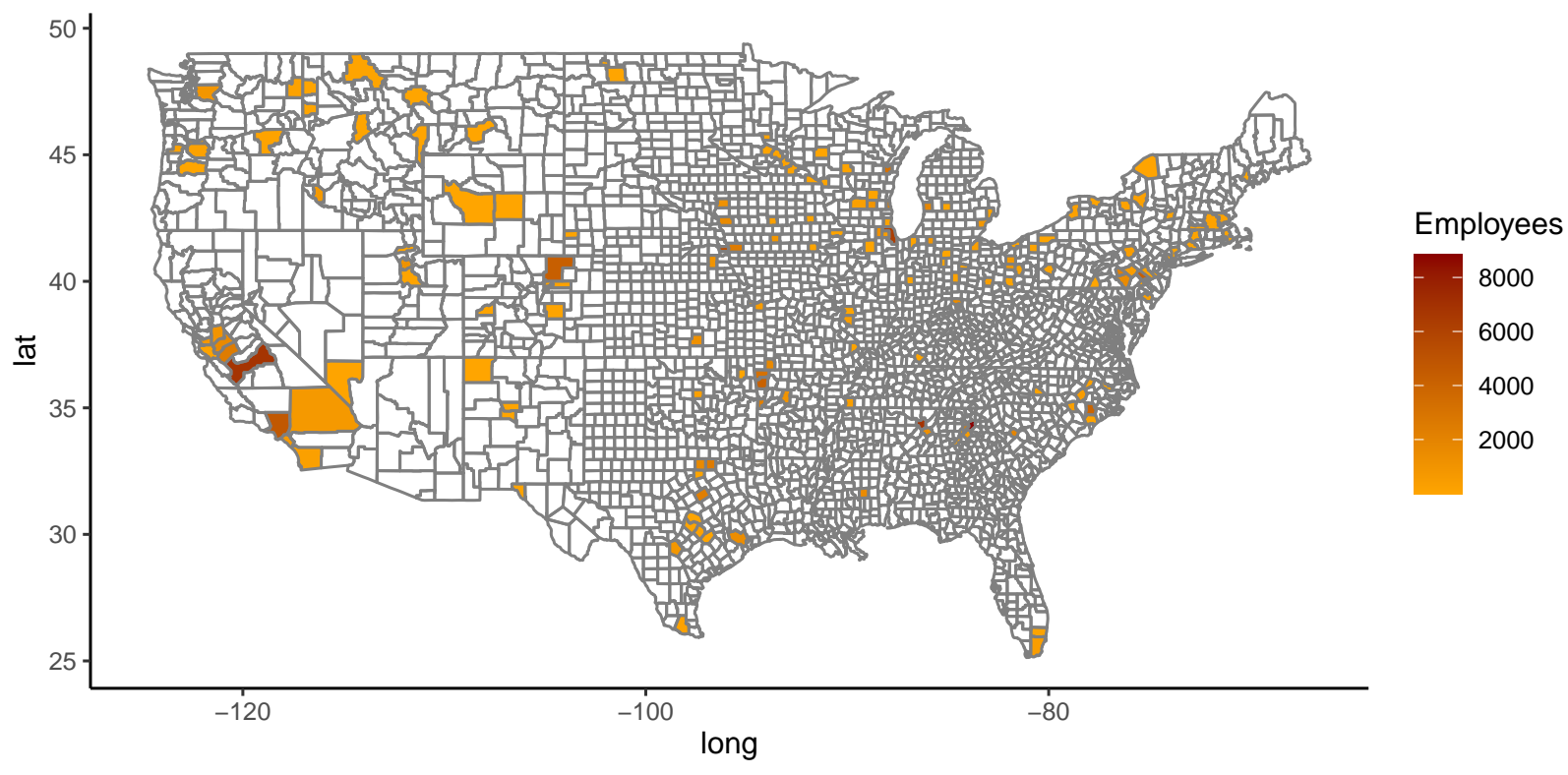

Weekly Wages

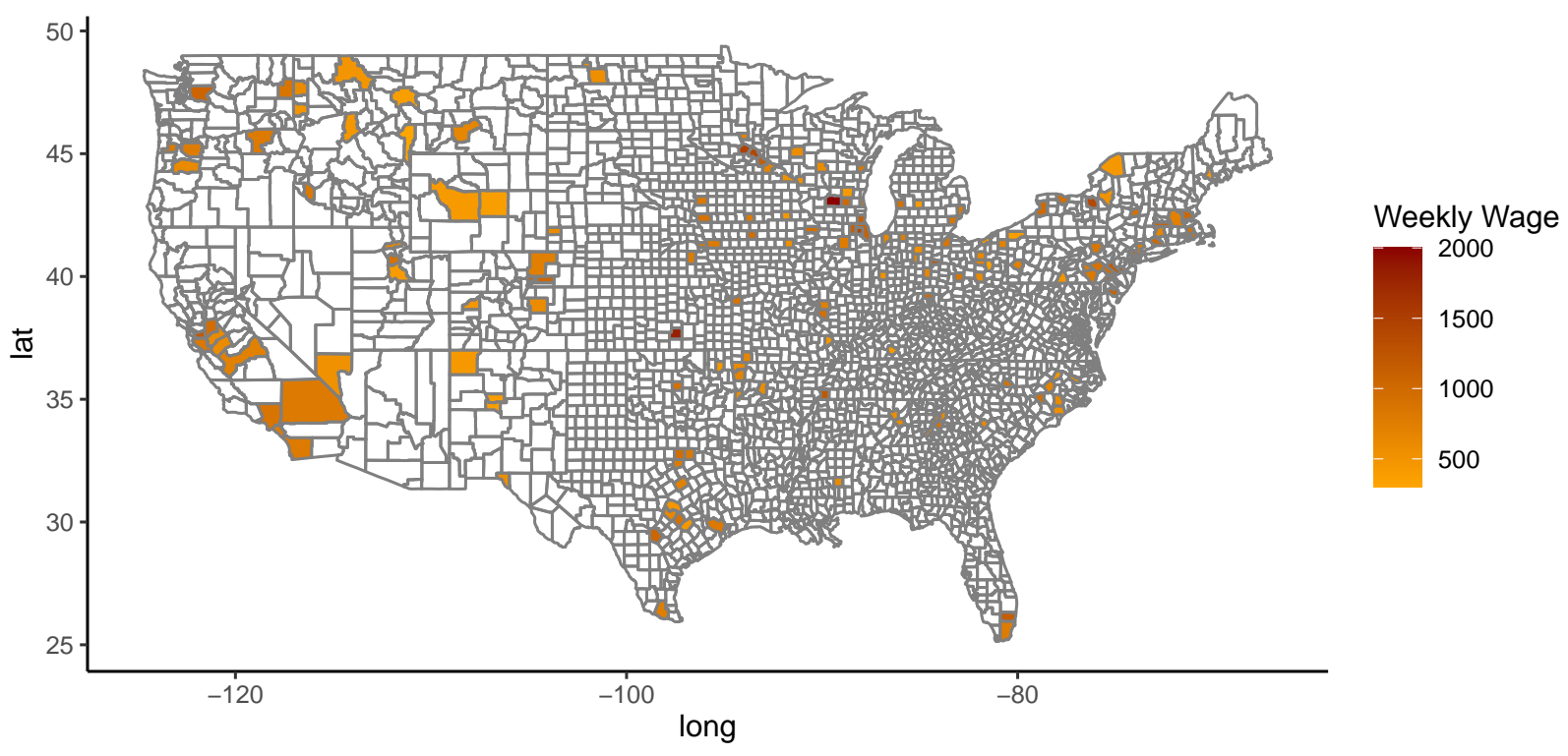

All data from Bureau of Labor Statistics. 
Figure 5: Wage and Employment Distributions for Food Manufacturing Sector and Animal Processing Sector, 2019

Food Manufacturing
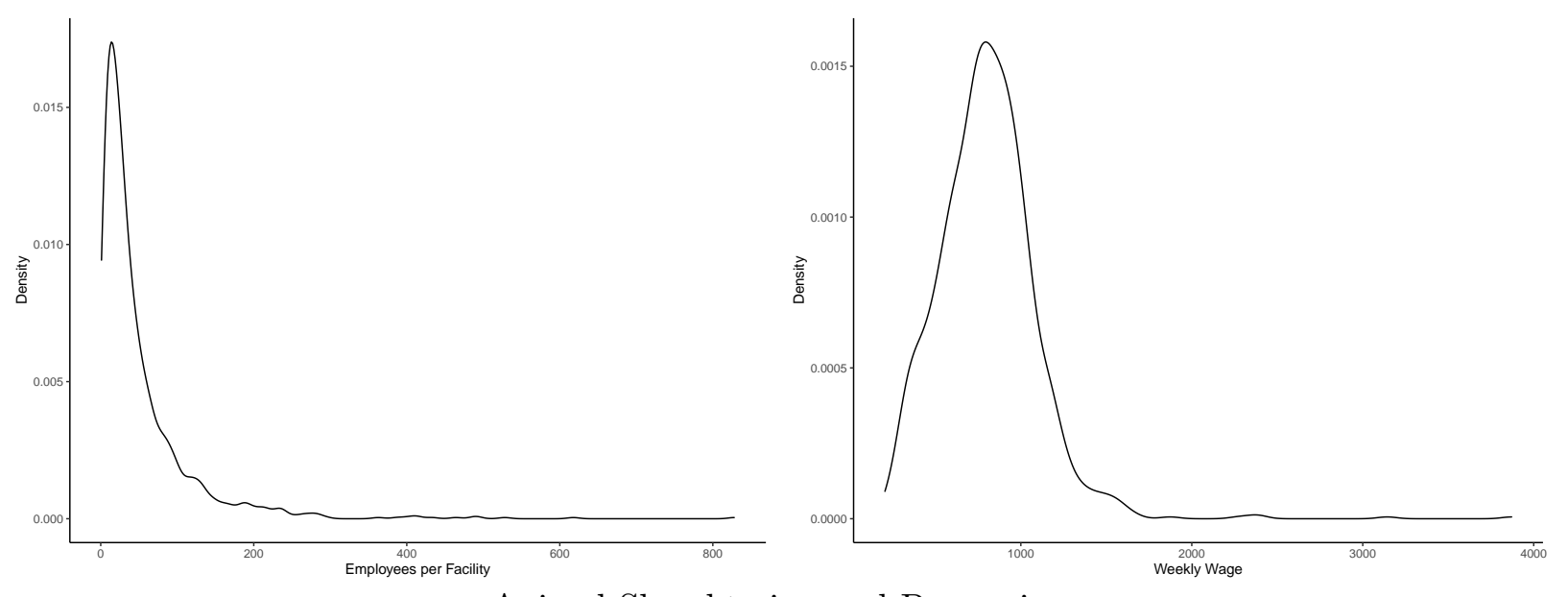

Animal Slaughtering and Processing
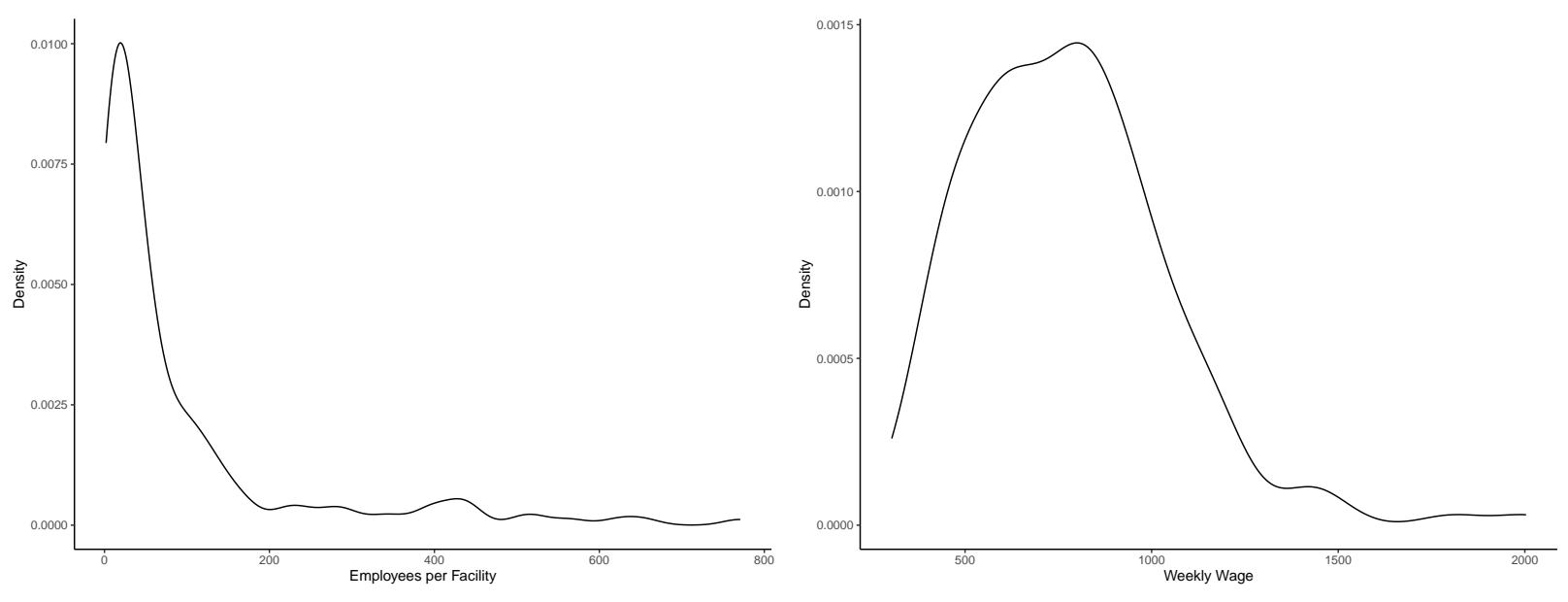

All data from Bureau of Labor Statistics. 
Figure 6: Food Manufacturing Sector Capacity Utilization and Output

(a) Food Manufacturing Capacity Utilization

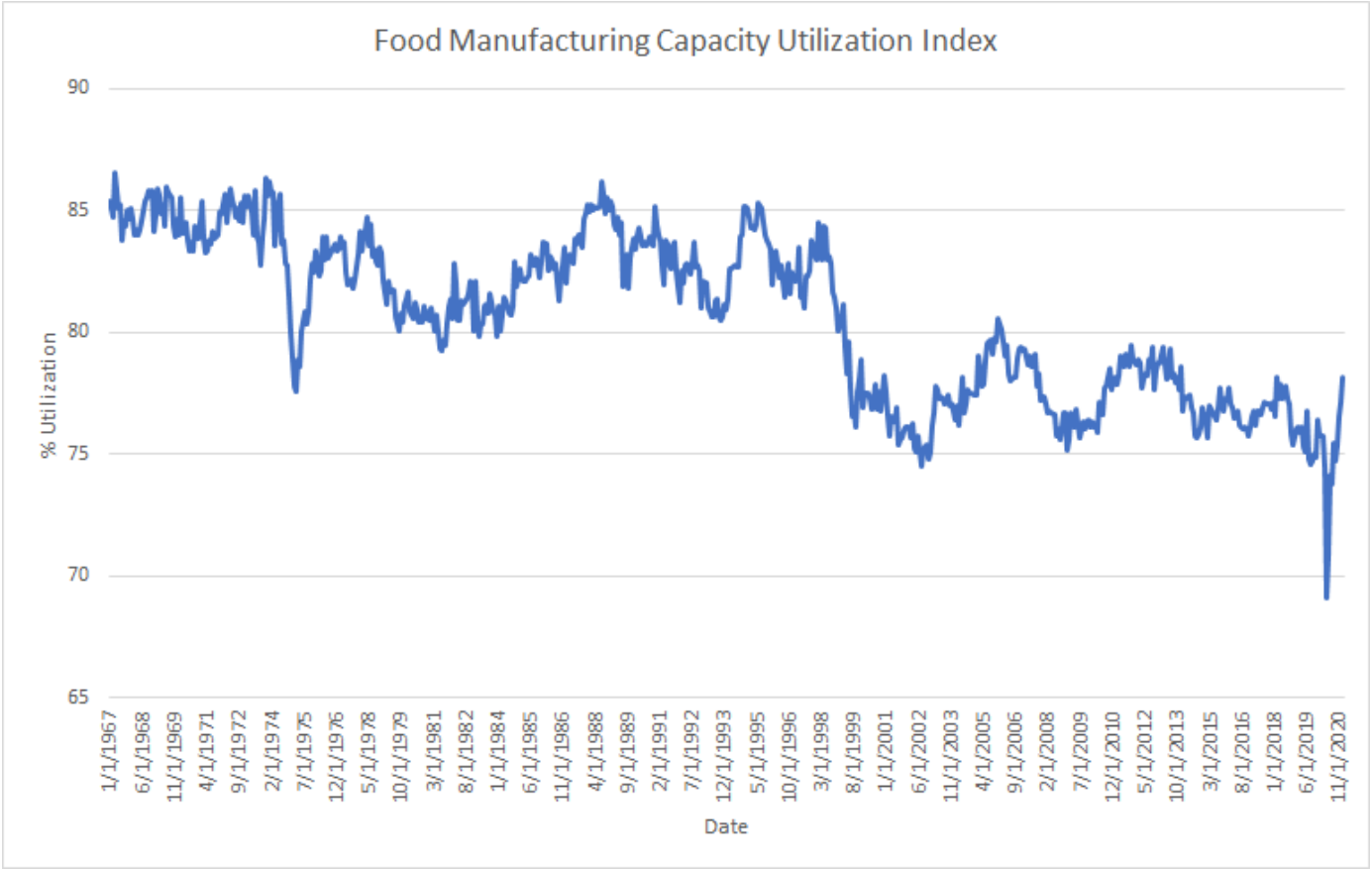

(b) Food Manufacturing Output

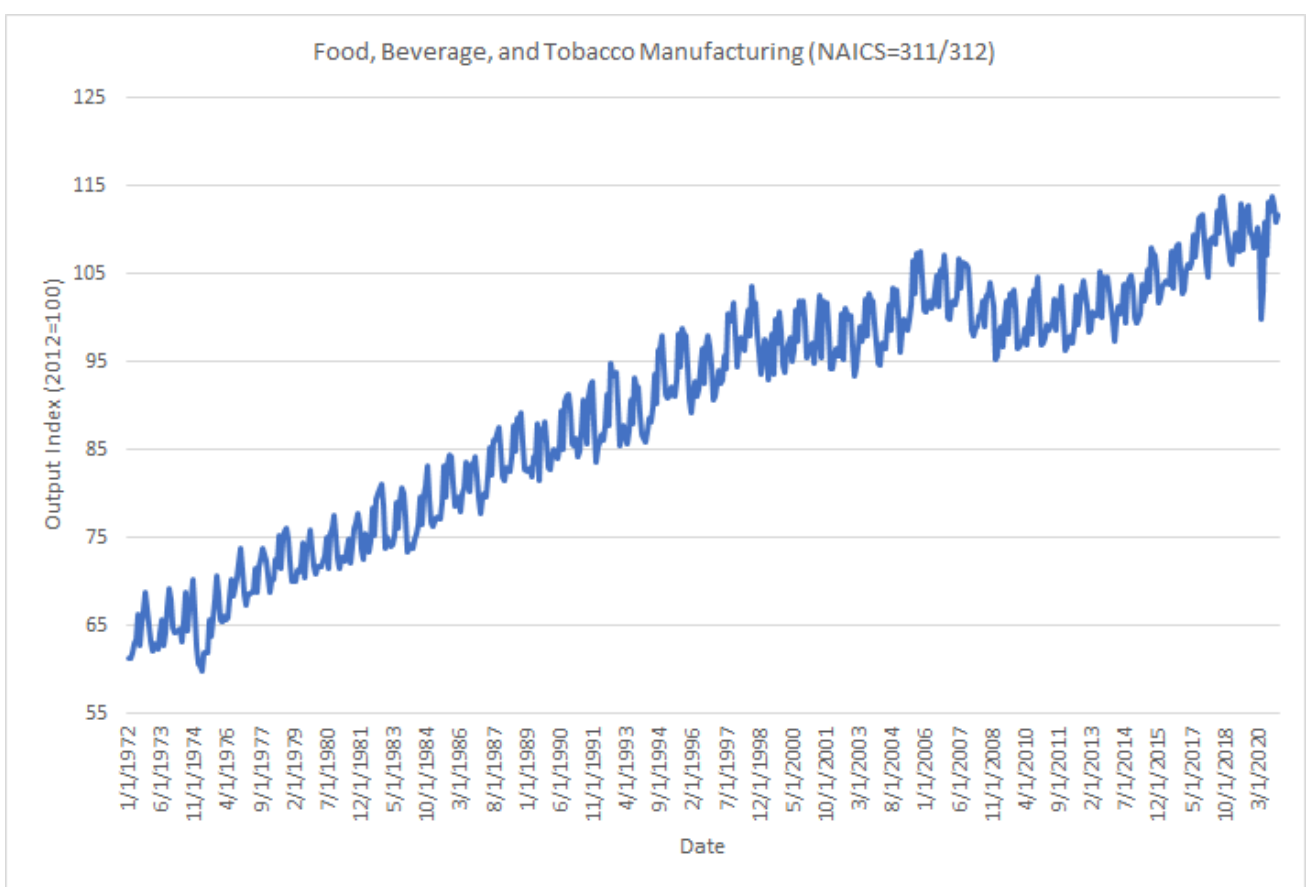


Figure 7: COVID-19 Related Changes in Average Weekly Wages in the Food Manufacturing Sector

(a) 2020 Quarter 1 Predicted vs. Actual Wages

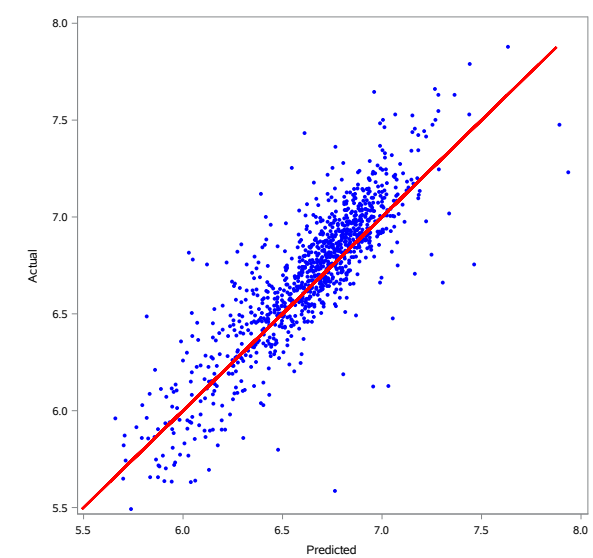

(b) 2020 Quarter 2 Predicted vs. Actual Wages

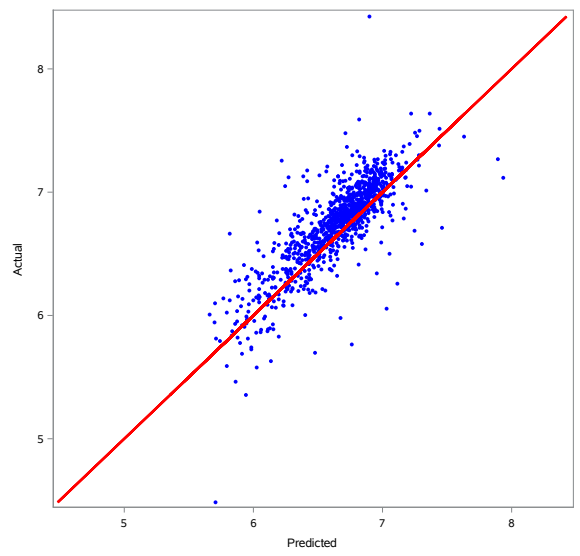

(c) 2020 Quarter 3 Predicted vs. Actual Wages

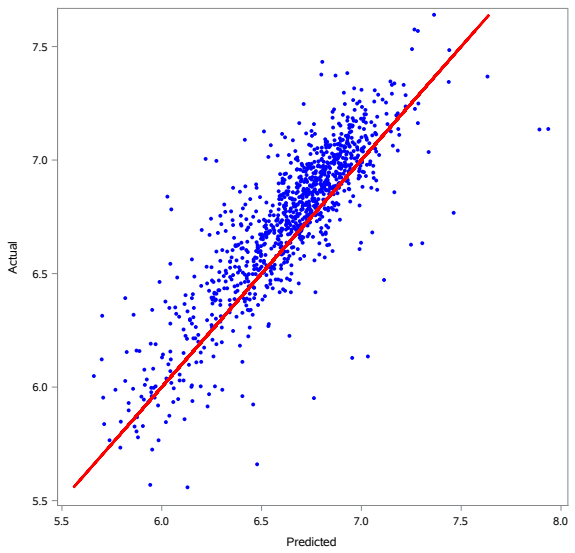




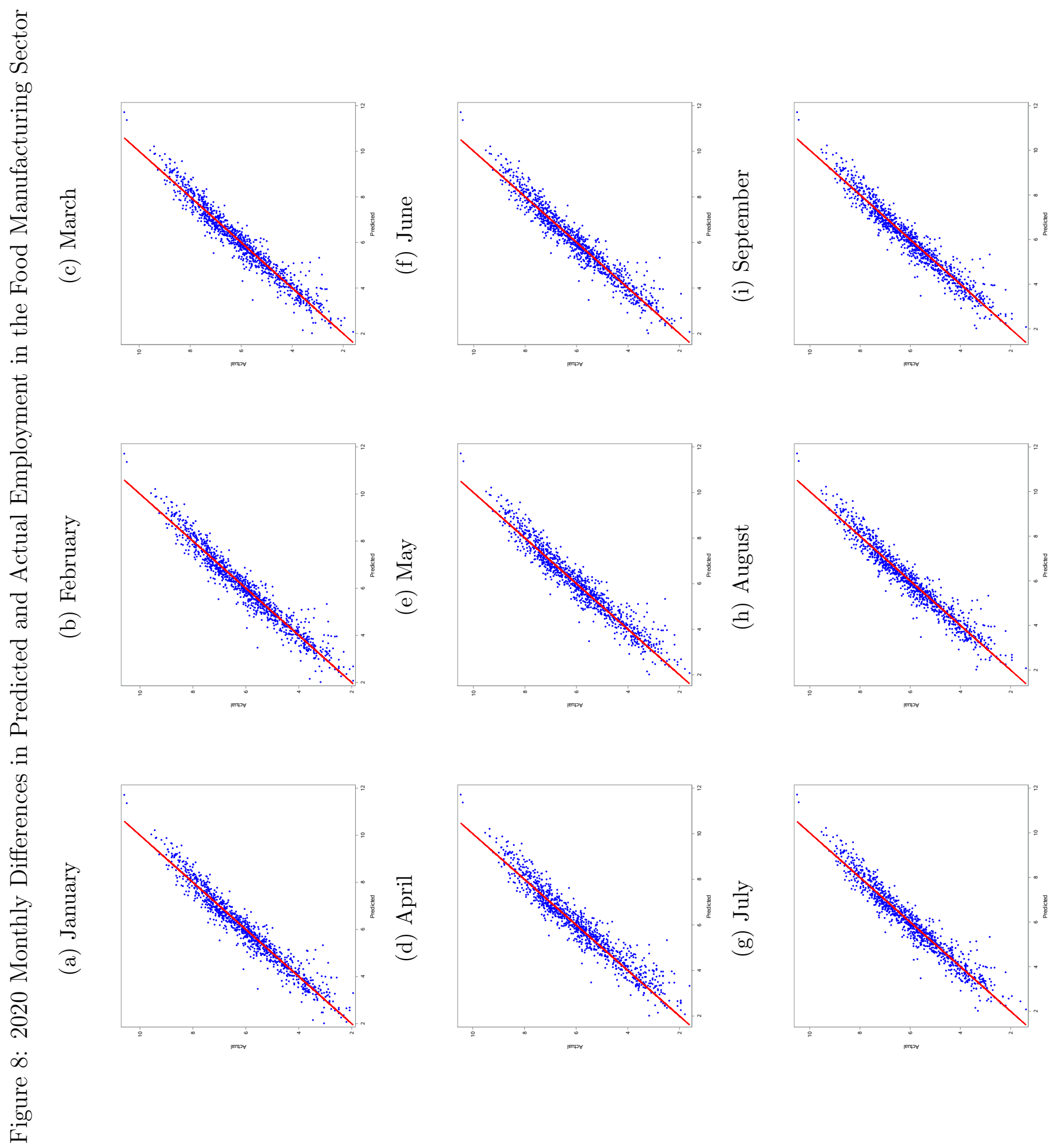


Figure 9: Unanticipated Decreases in 2020 Food Manufacturing Employment

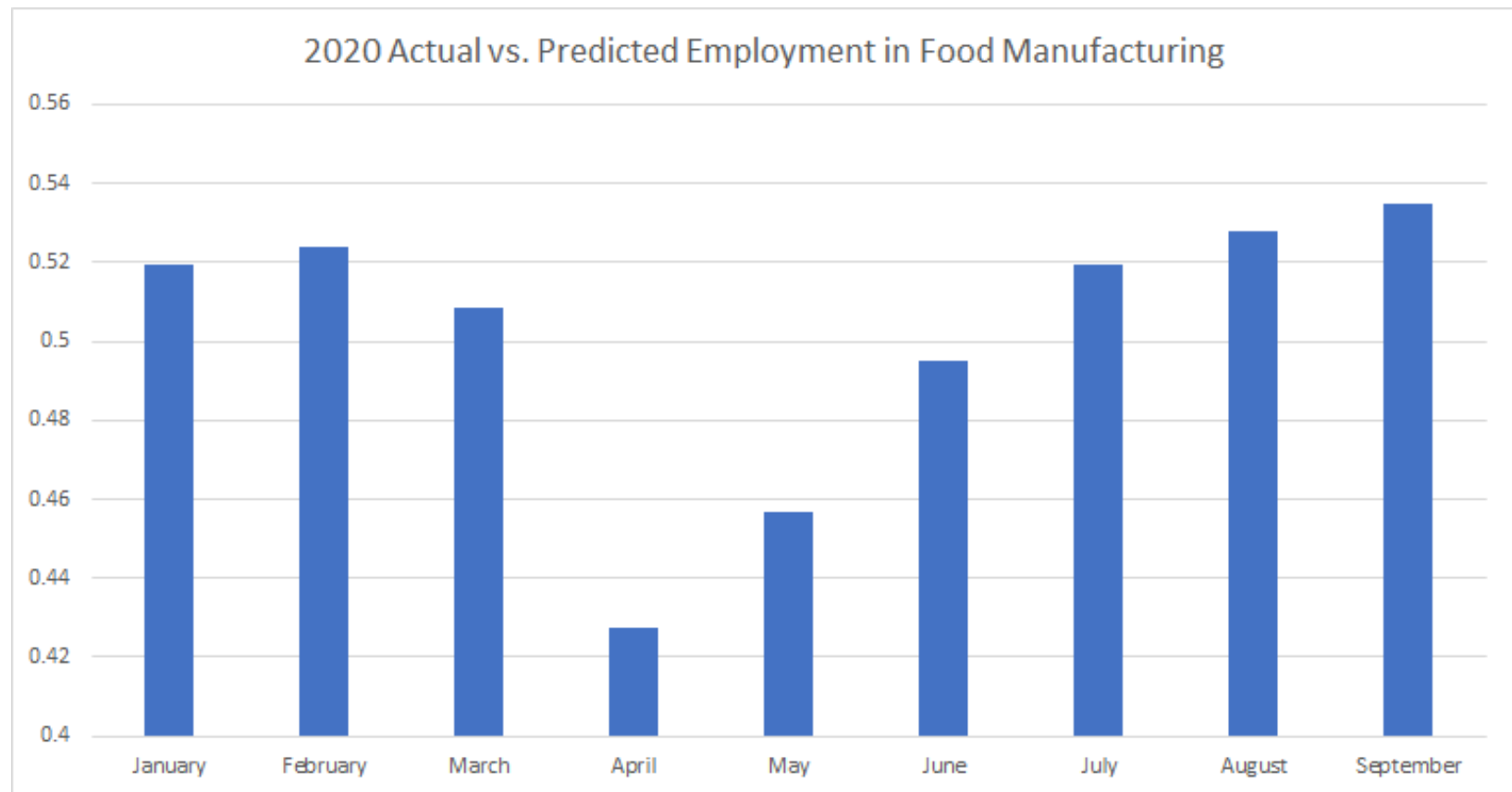


Figure 10: COVID-19 Related Changes in Average Weekly Wages in the Animal Processing Sector

(a) 2020 Quarter 1 Predicted vs. Actual Wages

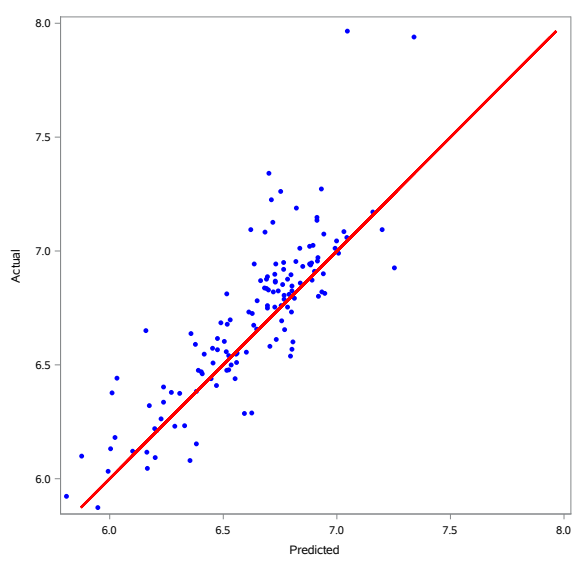

(b) 2020 Quarter 2 Predicted vs. Actual Wages

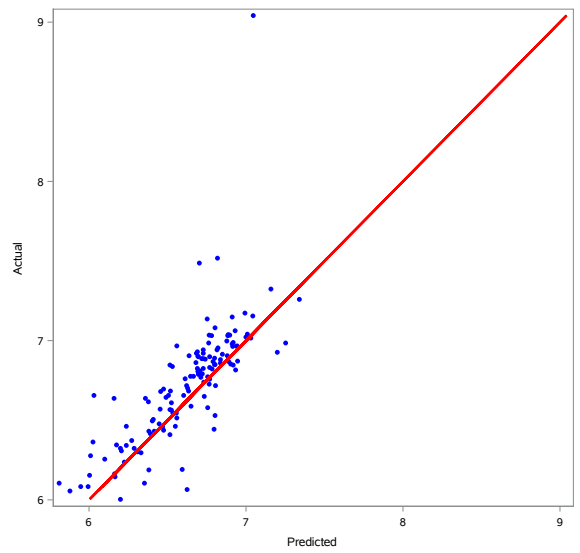

(c) 2020 Quarter 3 Predicted vs. Actual Wages

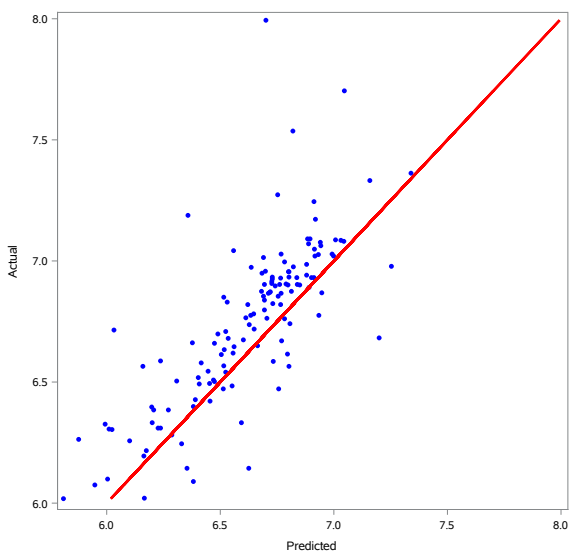




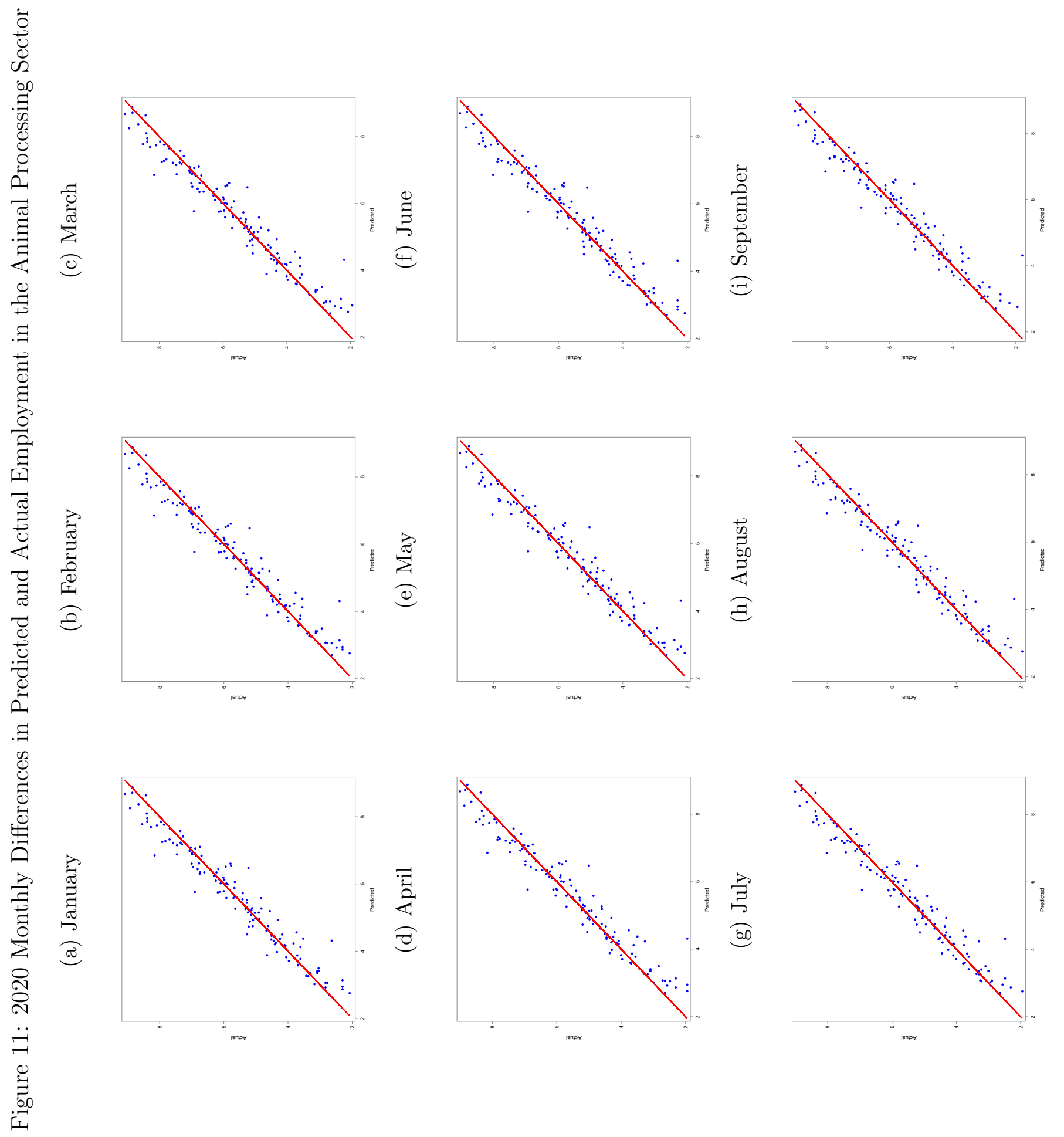


Figure 12: Unanticipated Decreases in 2020 Animal Processing Employment

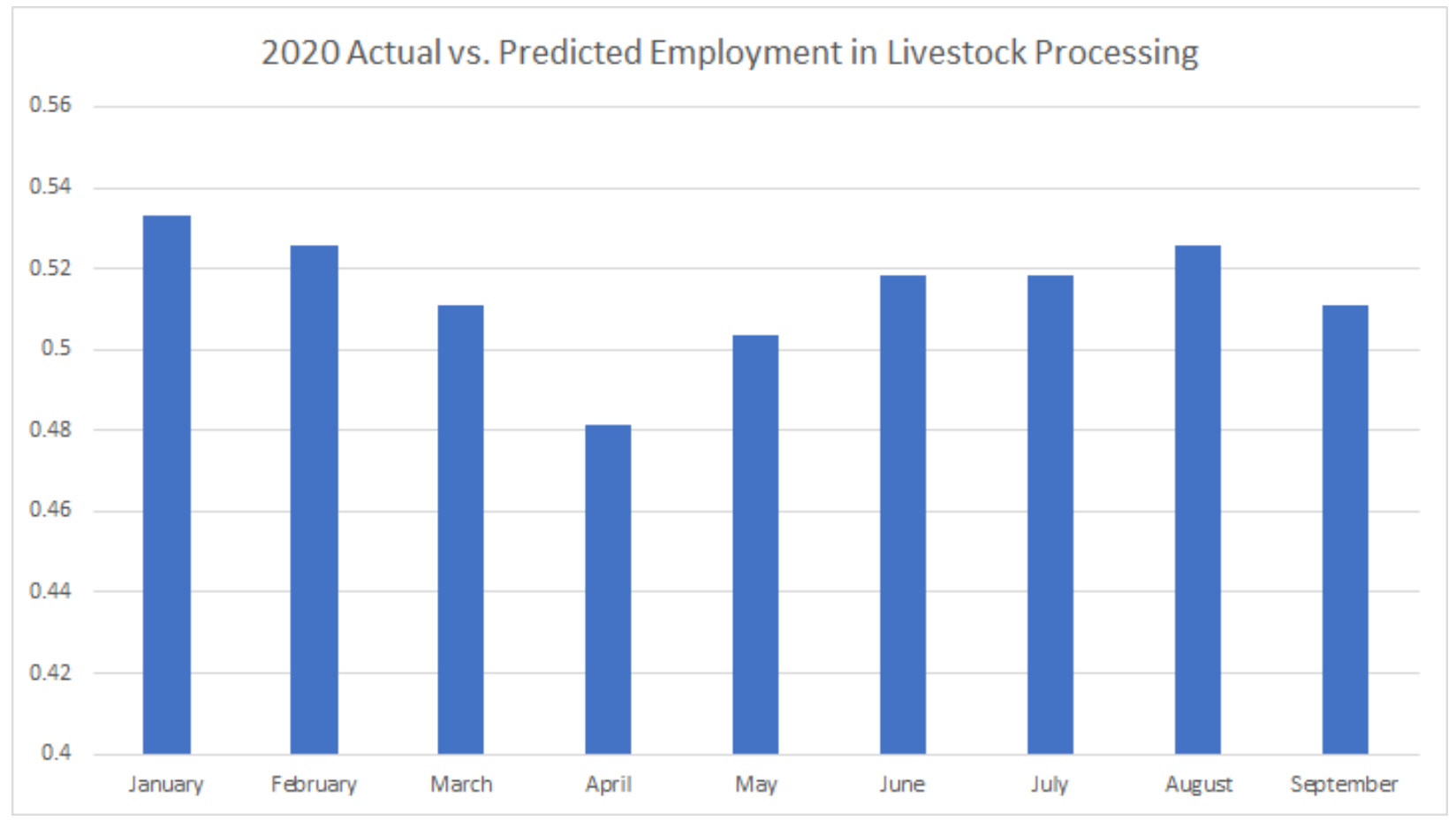




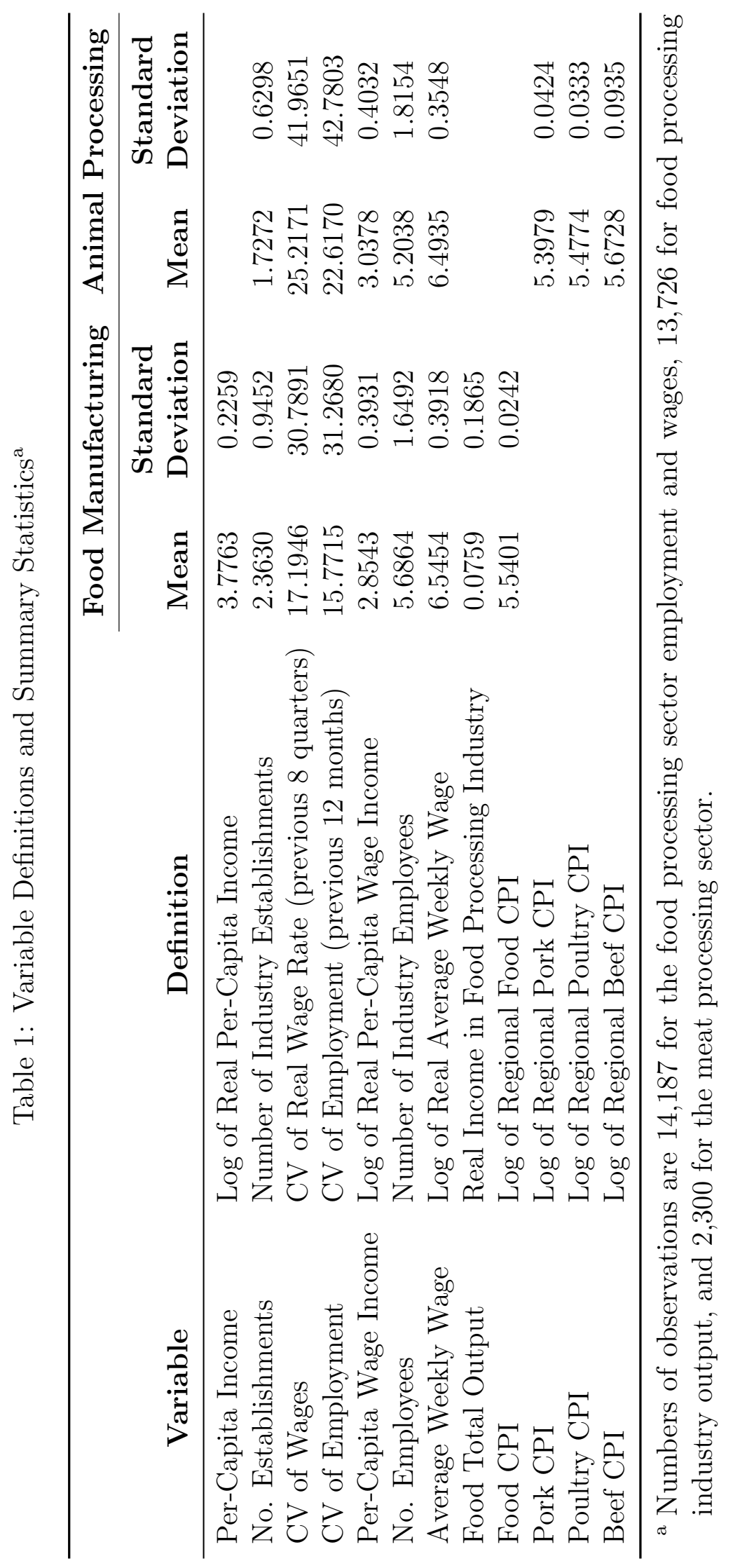


Table 2: Dynamic Panel Model of Food Manufacturing Sector Weekly Wages and Employment

\begin{tabular}{|c|c|c|c|c|c|c|}
\hline \multirow[b]{2}{*}{ Variable } & \multicolumn{3}{|c|}{ Average Weekly Wages } & \multicolumn{3}{|c|}{ No. Employees } \\
\hline & $\begin{array}{c}\text { Parameter } \\
\text { Estimate }\end{array}$ & $\begin{array}{l}\text { Standard } \\
\text { Error }\end{array}$ & $\begin{array}{c}\mathrm{t} \\
\text { Ratio }\end{array}$ & $\begin{array}{c}\text { Parameter } \\
\text { Estimate }\end{array}$ & $\begin{array}{l}\text { Standard } \\
\text { Error }\end{array}$ & $\begin{array}{c}\mathrm{t} \\
\text { Ratio }\end{array}$ \\
\hline Intercept & -2.1271 & 0.5975 & -3.56 & 1.2128 & 0.9462 & 1.28 \\
\hline${\text { Weekly } \text { Wage }_{t-1}}$ & 0.7347 & 0.0418 & 17.58 & & & \\
\hline No. Employees $_{t-1}$ & & & & 0.9009 & 0.0431 & 20.92 \\
\hline No. Employees $_{t-2}$ & & & & -0.0495 & 0.0180 & -2.75 \\
\hline No. Establishments & 0.0048 & 0.0129 & 0.37 & 0.3890 & 0.0281 & 13.84 \\
\hline Food CPI & 0.6334 & 0.1081 & 5.86 & -0.3186 & 0.1807 & -1.76 \\
\hline Weekly Wage & & & & 0.0797 & 0.0533 & 1.50 \\
\hline No. Employees & 0.0288 & 0.0086 & 3.37 & & & \\
\hline CV of Wages & 0.0044 & 0.0005 & 8.90 & -0.0013 & 0.0005 & -2.62 \\
\hline $\mathrm{CV}$ of Employment & -0.0041 & 0.0005 & -8.27 & 0.0006 & 0.0005 & 1.17 \\
\hline Per-Capita Wage Income & 0.0625 & 0.0288 & 2.17 & -0.0133 & 0.0456 & -0.29 \\
\hline$\ddot{R^{2}}$ & & 0.90 & & & 0.97 & \\
\hline Number of Cross Sections & & 1378 & & & 1378 & \\
\hline Time Series Length & & 12 & & & 12 & \\
\hline Number of Instruments & & 92 & & & 71 & \\
\hline
\end{tabular}




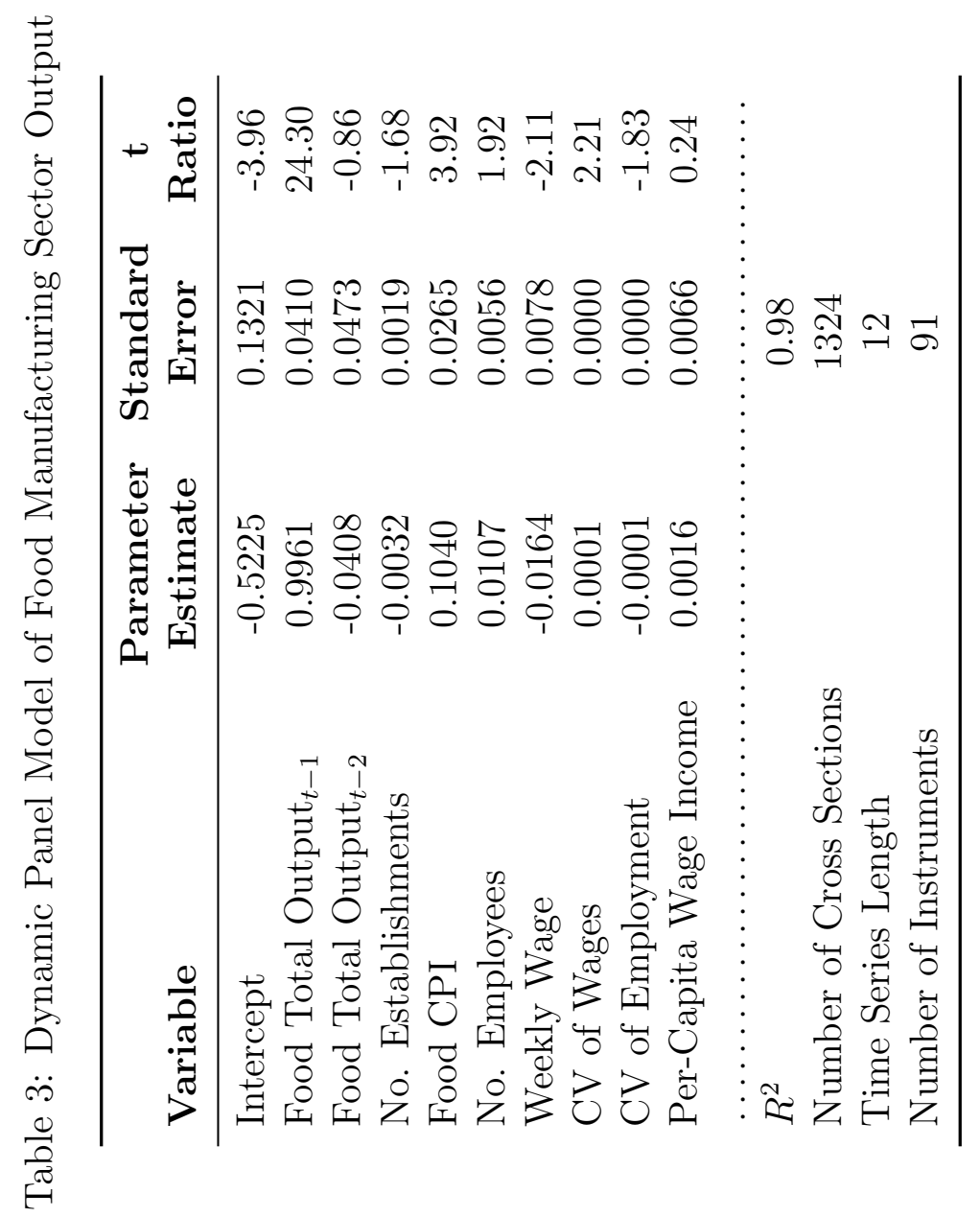




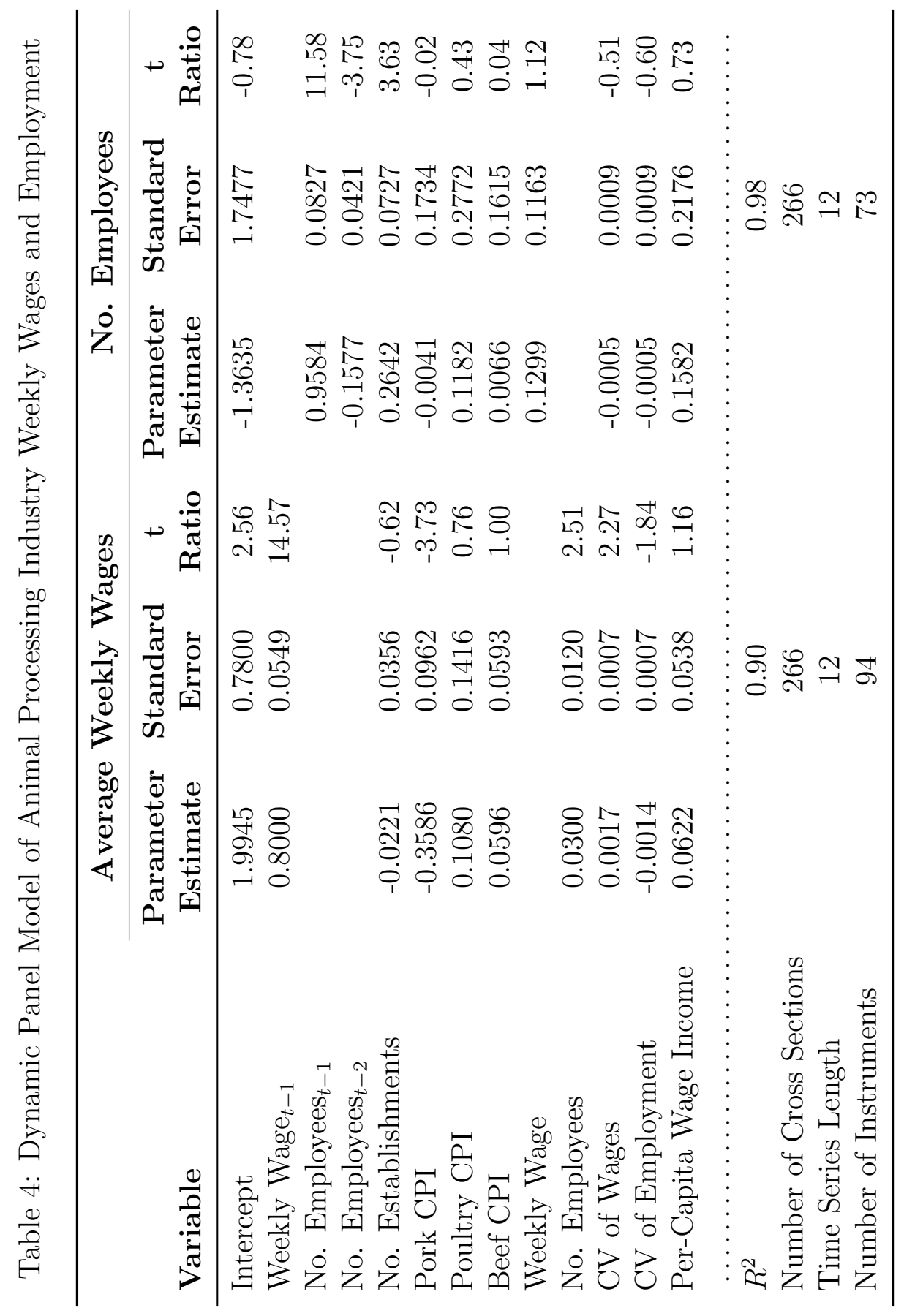

